\title{
Enhanced Photocatalytic Performance of CuFeO2- ZnO Heterostructures for Methylene Blue Degradation under Sunlight
}

Preethi Sudarsan ( $\sim$ preethi.sp21@gmail.com )

Pondicherry University https://orcid.org/0000-0001-7643-5287

Vivek Seethapathy

Pondicherry University

Priya Ranganathan

University of Madras

\section{Balakumar S}

University of Madras

Suresh Babu Krishnamoorthy

Pondicherry University

\section{Research Article}

Keywords: Hydrothermal, Photocatalysis, methylene blue, sunlight, heterostructures

Posted Date: March 1st, 2021

DOI: https://doi.org/10.21203/rs.3.rs-231641/v1

License: (c) (1) This work is licensed under a Creative Commons Attribution 4.0 International License. Read Full License

Version of Record: A version of this preprint was published at Journal of Materials Science: Materials in Electronics on August 2nd, 2021. See the published version at https://doi.org/10.1007/s10854-02106712-w. 
Enhanced photocatalytic performance of $\mathrm{CuFeO}_{2}-\mathrm{ZnO}$ heterostructures for methylene blue degradation under sunlight

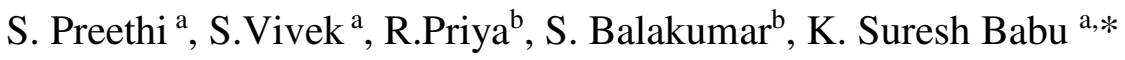

${ }^{a}$ Centre for Nanoscience and Technology, Madanjeet School of Green Energy Technologies, Pondicherry University (A Central University), Puducherry, 605014, India

${ }^{b}$ National Centre for Nanoscience and Nanotechnology, University of Madras, Tamilnadu, India.

* Corresponding Author

E mail: sureshbabu.nst@pondiuni.edu.in

Phone: +91-413-2654976 


\begin{abstract}
:
Development of heterostructures is one of the constructive strategies for enhancing the photocatalytic activity. Here, novel $\mathrm{CuFeO}_{2}-\mathrm{ZnO}$ heterostructures with different weight percentage $\left(\mathrm{CuFeO}_{2}=0.5,1,5,10 \%\right)$ were prepared by two-step precipitation-hydrothermal process. The structural confirmation was done by XRD and Raman analysis. The photocatalytic efficiency of the heterostructures was assessed by the degradation of methylene blue under sunlight. $\mathrm{CuFeO}_{2}-\mathrm{ZnO}$ heterostructures enhanced the photocatalytic performance compared to pure $\mathrm{ZnO}$ and $\mathrm{CuFeO}_{2}$. Among all, 5 wt $\%$ of $\mathrm{CuFeO}_{2}$ on $\mathrm{ZnO}$ exhibited $100 \%$ degradation with 16 fold faster kinetics than $\mathrm{ZnO}$. Time-resolved photoluminescent analysis revealed the increase in lifetime of charge carriers in the heterostructure. The band alignments of $\mathrm{ZnO}$ and $\mathrm{CuFeO}_{2}$, evaluated by Mott-Schottky revealed the existence of Type 1 heterostructures. Further, the heterostructures exhibited good recyclability. Thus, the present work demonstrates the use of p-type $\mathrm{CuFeO}_{2}$ and n-type $\mathrm{ZnO}$ heterostructures as potential photocatalysts.
\end{abstract}

Keywords: Hydrothermal; Photocatalysis; methylene blue; sunlight; heterostructures 


\section{Introduction}

The increasing adverse effects of industrial pollution on humans and environment thrust the development of research on clean energy and environment. Hence, toxic-free removal of these large quantities of harmful industrial effluents is the need of the hour to obtain clean water. Presently, research on photocatalysis has been extensively explored for responding to environmental pollution. Several kinds of study on $\mathrm{TiO}_{2}$ [1], $\mathrm{ZnO}$ [2], $\mathrm{ZnS}$ [3], $\mathrm{CdS}$ [4], CdSe, $\mathrm{V}_{2} \mathrm{O}_{5}[5], \mathrm{WO}_{3}[6]$, and $\mathrm{Fe}_{2} \mathrm{O}_{3}$ [7] have proven their usage for photocatalytic removal of organic azo dyes. Among all these, $\mathrm{ZnO}$, the n-type semiconductor has picked up steam due to its low cost, easily controlled morphology, high redox potential, photonic and oxidation resistive and non-toxic nature. However, due to its wide bandgap $(\sim 3.2 \mathrm{eV})$, the optical absorption is constrained to UV region which is only $4 \%$ of the total sunlight radiation. This mitigates the use of naturally available sunlight as the source of energy. Further, in $\mathrm{ZnO}$, the excited electron recombines with hole faster and decreases the free carrier concentration required for degradation, therefore hindering the photocatalytic performance [8]. To promote the absorption of these semiconductors in the visible region and to suppress the electron-hole recombination, researchers adopted several strategies such as introducing dopants $[9,10]$, manoeuvring the size and shape of the photocatalytic materials [11,12], formation of heterojunctions. Among these, contriving the photocatalyst materials by forming heterojunctions with other semiconductor oxides would pave the way for enhanced photocatalytic activity by forming an interfacial electric field which would effectively separate the charge-carriers. Meng et al. identified an enhanced photocatalytic $\mathrm{CO}_{2}$ reduction by $\mathrm{Ni}(\mathrm{OH})_{2} / \mathrm{TiO}_{2}$ [13]. $\mathrm{AgI} / \mathrm{BiVO}_{4}$ has shown $43 \%$ higher photocatalytic activity compared to $\mathrm{BiVO}_{4}$ [14]. Jiang et al. developed $\mathrm{TiO}_{2}-\mathrm{ZnO}$ heterojunctions for decolourisation of C.I. Basic Blue 41 [15]. Udin et al. reported enhanced photocatalytic activity for $\mathrm{SnO}_{2}-\mathrm{ZnO}$ heterostructure towards methylene blue degradation [16]. Among many heterojunctions viz. metal-semiconductor, semiconductor-semiconductor 
(p-p type, $p-n$ type, $n-n$ type), $p$-n heterojunctions have shown to be favouring effective charge separation, longer lifetime and rapid charge transfer. $\mathrm{CuO}-\mathrm{ZnO}$ p-n type heterostructure has shown better performance for gas sensing and photocatalytic degradation $[17,18,19]$. Shaheer et al. reported that reduced $\mathrm{GO}$ supported $\mathrm{TiO}_{2}-\mathrm{In}_{0.5} \mathrm{WO}_{3}$ showing a 12 fold improvement in comparison to bare $\mathrm{TiO}_{2}[20]$. Similarly, $\mathrm{ZnO}-\mathrm{CdS}, \mathrm{ZnO}-\mathrm{ZnS}, \mathrm{ZnO}-\mathrm{CuO}, \mathrm{ZnO}-\mathrm{GaN}$ heterostructures have shown increased performance in comparison to pristine $\mathrm{ZnO}$. $\mathrm{ZnOSe} / \mathrm{ZnO} /$ boron doped $\mathrm{ZnO}$ exhibited reduced electron-hole recombination rate compared to pristine $\mathrm{ZnO}$. $\mathrm{ZnO} / \mathrm{NiFe}_{2} \mathrm{O}_{4}$ nanocomposite exhibited enhanced degradation efficiency compared to $\mathrm{ZnO}$ [21]. Further to enhance the visible light-harvesting, heterojunction formation with narrow bandgap semiconductors has found to be advantageous. Recently p-type delafossite materials such as $\mathrm{CuAlO}_{2}, \mathrm{CuFeO}_{2}$ have received considerable attraction as photocathodes for photoelectrochemical water splitting and hydrogen evolution reaction and as transparent conducting oxides [22,23]. In particular, $\mathrm{CuFeO}_{2}$ delafossite has drawn great attention due to its absorption in the visible region with a narrow bandgap energy of $\sim 1.5 \mathrm{eV}$. But it suffers meagre transport properties due to higher electron-hole recombination rate.

Hence, to address these challenges, we report the construction of heterostructure between a p-type narrow bandgap $\left(\mathrm{CuFeO}_{2}\right)$ and n-type wide bandgap semiconductor $(\mathrm{ZnO})$ for improved methylene blue degradation and the results have been correlated to the physicalchemical properties of the material. Thus this paper would provide a scientific outlook to further design novel heterostructures for enhanced solar harvesting.

\section{Experimental procedure}

\section{Synthesis of pure $\mathrm{ZnO}$}

Zinc oxide $(\mathrm{ZnO})$ was synthesised by precipitation method using zinc nitrate hexahydrate $\left(\mathrm{Zn}\left(\mathrm{NO}_{3}\right)_{2} \cdot 6 \mathrm{H}_{2} \mathrm{O}\right.$, Himedia) and sodium hydroxide $(\mathrm{NaOH}$, Himedia) as precursors. $14 \mathrm{~g}$ of 
zinc nitrate was dissolved in distilled water. To this, $3 \mathrm{M} \mathrm{NaOH}$ was added to maintain the $\mathrm{pH}$ of 11 . The resultant solution was stirred for 12 hours forming a precipitate. Then the precipitate was centrifuged and dried at $80{ }^{\circ} \mathrm{C}$ overnight. The dried powder was calcined at a temperature of $500{ }^{\circ} \mathrm{C}$ for 4 hours.

\section{Synthesis of pure $\mathrm{CuFeO}_{2}$}

$\mathrm{CuFeO}_{2}$ (CFO) was synthesised by hydrothermal method. An aqueous solution of copper $\left(\mathrm{Cu}\left(\mathrm{NO}_{3}\right)_{2} \cdot 6 \mathrm{H}_{2} \mathrm{O}\right.$, Himedia and iron nitrates $\left(\mathrm{Fe}\left(\mathrm{NO}_{3}\right)_{3} .9 \mathrm{H}_{2} \mathrm{O}\right.$, Himedia) was prepared by dissolving in stoichiometric ratio. To this, $3 \mathrm{M} \mathrm{NaOH}$ was added to achieve a $\mathrm{pH}$ of 14 . The solution was stirred for 30 minutes, then $1 \mathrm{ml}$ of hydrazine hydrate was added to the mixture. Then the solution was decanted to a Teflon vessel which was later autoclaved at $180{ }^{\circ} \mathrm{C}$ for 24 hours. After this process, the sample was washed 3 times, two times with double distilled water and once with ethanol. The resultant nanopowder was collected after drying at $80^{\circ} \mathrm{C}$ overnight.

\section{Synthesis of $\mathrm{CuFeO}_{2}-\mathrm{ZnO}$}

Different weight ratios of $\mathrm{CuFeO}_{2}-\mathrm{ZnO}(\mathrm{xCF}-\mathrm{ZnO}, \mathrm{x}=0.5,1,5,10 \%) \mathrm{p}-\mathrm{n}$ heterostructures were synthesized by hydrothermal method. The calcined $\mathrm{ZnO}$ was dispersed in distilled water, and then the stoichiometric amount of the nitrates of $\mathrm{Cu}$ and $\mathrm{Fe}$ were added. Then, $\mathrm{NaOH}$ and hydrazine hydrate was added similarly followed for the $\mathrm{CuFeO}_{2}$.

\section{Characterization}

The phase analysis was done using X-ray diffractometer (Rigaku, Ultima IV) with $\mathrm{Cu}$ $\mathrm{K}_{\alpha}$ radiation $(\lambda=1.5406 \AA)$ at a scan rate of $0.02^{\circ}$ per second in the $2 \theta$ range between 20 and $80^{\circ}$. The Raman spectra were obtained by Renishaw, RM 2000 with a laser excitation wavelength of $785 \mathrm{~nm}$ and $0.3 \mathrm{~mW}$ power. The morphological characterization was done using a Scanning Electron Microscope (Hitachi, Model-S-34000N). The optical analysis was carried UV-Vis spectrophotometer (Shimadzu, UV- 3600). Time-resolved photoluminescence (TRPL) 
analysis was done using fluorescence lifetime spectrometer (Jobin Yvon, FLUOROLOG-FL311). The electrochemical analysis was done using PARSTAT 4000A potentiostat. Mott Schottky and electrochemical impedance analysis of the heterostructures were carried out using a three-electrode cell consisting of $\mathrm{Ag} / \mathrm{AgCl}$ as reference electrode and platinum as counter electrode.

\section{Results and discussion}

\section{X-Ray Diffraction}

Phase identification of the samples was done by X-ray diffraction analysis. Fig. 1 shows the $\mathrm{XRD}$ pattern of pristine $\mathrm{ZnO}, \mathrm{CuFeO}_{2}$ and $\mathrm{xCF}-\mathrm{ZnO}(\mathrm{x}=0.5,1,5$ and 10$)$. All the peaks were sharp, indicating the crystalline structure of all the prepared samples. The diffraction peaks at $2 \Theta=31.6^{\circ}, 34.5^{\circ}, 36.2^{\circ}, 47.6^{\circ}, 56.7^{\circ}, 62.9^{\circ}, 66.4^{\circ}, 67.9^{\circ}$ and $69.1^{\circ}$ corresponds to the (100), (002), (101), (102), (110), (103), (200), (112) and (201) crystal planes, respectively, of hexagonal wurtzite structure of $\mathrm{ZnO}$ with space group P6 3 mc (JCPDS: 36-1451). Diffraction peaks at $31.2^{\circ}, 34.5^{\circ}, 35.7^{\circ}, 40.2^{\circ}, 55.2,61.3^{\circ}, 64.7^{\circ}, 70.2^{\circ}$ in $\mathrm{CFO}$ can be ascribed to (006), (101), (012), (104), (018), (110), (010) and (011) crystal planes of pure rhombohedral delafossite $\mathrm{CuFeO}_{2}$ with the R3m space group (JCPDS: 39-0246).

In 0.5 and $1 \mathrm{CF}-\mathrm{ZnO}$, no peak other than corresponding to $\mathrm{ZnO}$ was observed. But in 5 and $10 \mathrm{CF}-\mathrm{ZnO}$, besides diffraction peaks of $\mathrm{ZnO}$, additional peaks were observed at $35.3^{\circ}$ and $40.7^{\circ}$ (denoted by arrow) which are characteristic of $\mathrm{CuFeO}_{2}$. This substantiates the presence of both $\mathrm{ZnO}$ and $\mathrm{CuFeO}_{2}$. The peaks other than (012) and (104) are not distinct due to the low scattering ability of $\mathrm{CFO}$ on $\mathrm{ZnO}$. The absence of peaks specific to $\mathrm{CuFeO}_{2}$ in $\mathrm{xCF}-\mathrm{ZnO}(\mathrm{x}<5)$ is due to the low concentration of $\mathrm{CuFeO}_{2}$ which might be below the XRD detection limit. No additional peak implies the purity of the synthesised material. The calculated lattice parameter of $\mathrm{ZnO}$ was found to be $\mathrm{a}, \mathrm{b}=0.3348 \mathrm{~nm}, \mathrm{c}=0.569 \mathrm{~nm}$ and $\mathrm{CFO}$ was $\mathrm{a}=\mathrm{b}=0.304 \mathrm{~nm}$, 
$\mathrm{c}=1.702 \mathrm{~nm}$. No peak shift was observed in $\mathrm{xCF}-\mathrm{ZnO}$ and the lattice parameter of $\mathrm{ZnO}$ remained constant substantiating the successful formation of heterostructure without doping.

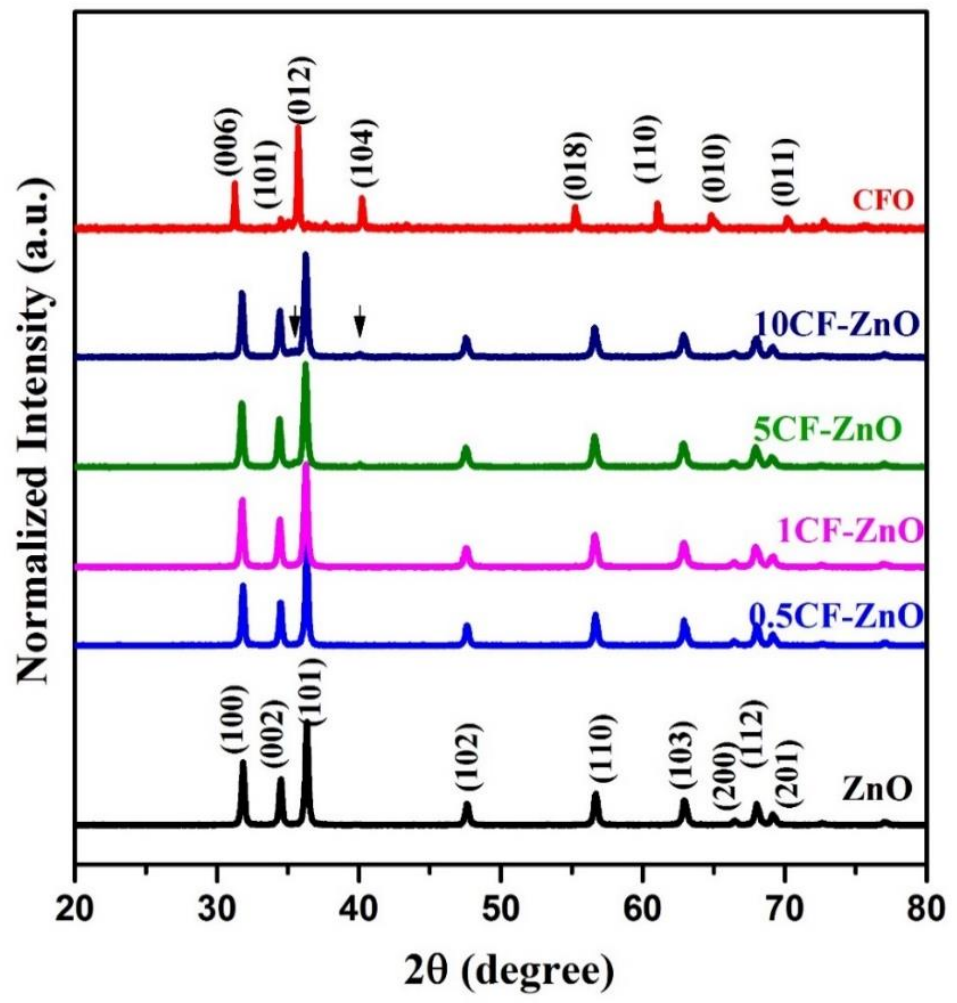

Fig. 1 XRD pattern of pure $\mathrm{ZnO}, \mathrm{xCF}-\mathrm{ZnO}(\mathrm{x}=0.5,1,5,10)$ and pure

CFO. The peaks marked with arrow corresponds to $\mathrm{CuFeO}_{2}$

The crystallite size of the synthesised sample was computed by Debye-Scherer's formula. The crystallite size of $\mathrm{ZnO}(29.6 \pm 2 \mathrm{~nm})$ did not vary since $\mathrm{ZnO}$ was first synthesised using precipitation method and then hydrothermally treated to form a p-n heterostructure. This denotes that the hydrothermal condition did not affect the previously synthesised $\mathrm{ZnO}$. The crystallite size of CFO was calculated to be $41.2 \pm 3 \mathrm{~nm}$, while that of $10 \mathrm{CF}-\mathrm{ZnO}$ was calculated to be $18 \pm 2 \mathrm{~nm}$. The decreased crystallite size in the composite is due to the hindrance in the nucleation of the host structure $\left(\mathrm{CuFeO}_{2}\right)$ in the presence of foreign $\mathrm{ZnO}$.

\section{Raman spectroscopy}

The vibrational properties of the heterostructures were examined by Raman spectroscopy. Fig. 2 depicts the Raman spectra of $\mathrm{xCF}$ - ZnO system. As per group theory, the optical modes present in a wurtzite $\mathrm{ZnO}$ are given in equation (1) 


$$
\Gamma o p t=A_{1}+2 B_{2}+E_{1}+2 E_{2}
$$

where $A_{1}$ and $E_{1}$ are active modes which are further divided into longitudinal optical $\left(A_{1} L O\right.$ and $\left.\mathrm{E}_{1} \mathrm{LO}\right)$ and transverse optical ( $\mathrm{A}_{1} \mathrm{TO}$ and $\left.\mathrm{E}_{1} \mathrm{TO}\right)$ modes. In this, $\mathrm{A}_{1}, \mathrm{E}_{1}$ and $\mathrm{E}_{2}$ represents Raman-active modes while $\mathrm{B}_{2}$ are Raman inactive modes.

The prominent peak at $436 \mathrm{~cm}^{-1}$ corresponds to the $\mathrm{E}_{2}$ mode of vibration in $\mathrm{ZnO}$ lattice which

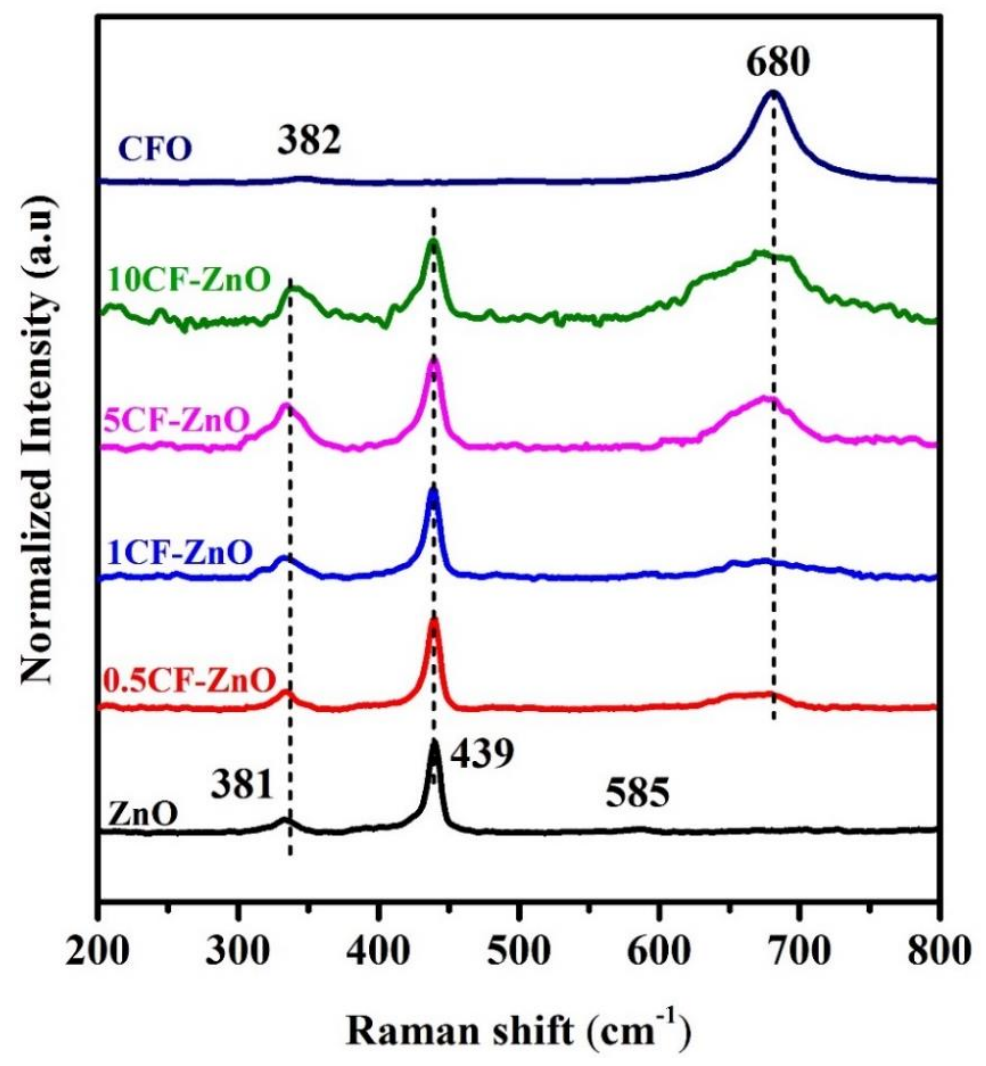

Fig. 2 Raman spectra of $\mathrm{ZnO}, \mathrm{CFO}$ and $\mathrm{xCF}-\mathrm{ZnO}$ system

represents the parallel vibration of paired $\mathrm{Zn}$ and $\mathrm{O}$ atom in the same direction. Besides the $\mathrm{E}_{2}$ band, the small intense peaks at 381 and $585 \mathrm{~cm}^{-1}$ is accredited to $\mathrm{A}_{1}$ (TO) mode and $\mathrm{A}_{1}(\mathrm{LO}) / \mathrm{E}_{1}(\mathrm{LO})$, respectively. The peak at 332 is due to the multi phonon scattering modes that can be assigned to the optical phonon overtone with $\mathrm{A}_{1}$ symmetry [24]. $\mathrm{CuFeO}_{2}$ delafossite with rhombohedral structure contains twelve vibrational modes at the zone centre, represented as

$$
\text { Гopt }=A_{1 g}+E_{g}+3 A_{2 u}+3 E_{u} \text {. }
$$


Where subscript $\mathrm{g}$ represents Raman active modes, subscript $\mathrm{u}$ denotes the infrared active modes. CFO exhibits $A_{1 g}$ and $E_{g}$ mode of vibrations at 680 and $382 \mathrm{~cm}^{-1}$, respectively. In xCF$\mathrm{ZnO}$ system, the peak at $680 \mathrm{~cm}^{-1}$ emerges with the increase in concentration from 0.5 to $10 \mathrm{CF}$ $\mathrm{ZnO}$, which is characteristic to the vibration of rhombohedral $\mathrm{CuFeO}_{2}$. Further, no shift in the representative peaks of $\mathrm{CFO}$ and $\mathrm{ZnO}$ was observed denoting the absence of $\mathrm{Cu}$ or $\mathrm{Fe}$ in $\mathrm{ZnO}$ lattice.

\section{Morphological study}

The surface morphology of the heterostructure was inspected by scanning electron microscope. Fig. 3 depicts the SEM images of 0.5CF- $\mathrm{ZnO}$ and 5CF-ZnO. The heterostructure exhibits spherical morphology. The average particle size was acquired by calculating the particle size of around 100 particles. Inset represents the histogram of particle size distribution. The histogram exhibited lognormal distribution with a mean particle size of 113 and $119 \mathrm{~nm}$ for $0.5 \mathrm{CF}-\mathrm{ZnO}$ and $5 \mathrm{CF}-\mathrm{ZnO}$, respectively. The samples exhibited separate particles projecting the homogeneity of the samples. Further, no change in the morphology of $\mathrm{ZnO}$ occurred upon forming $\mathrm{CF}-\mathrm{ZnO}$ heterostructure.
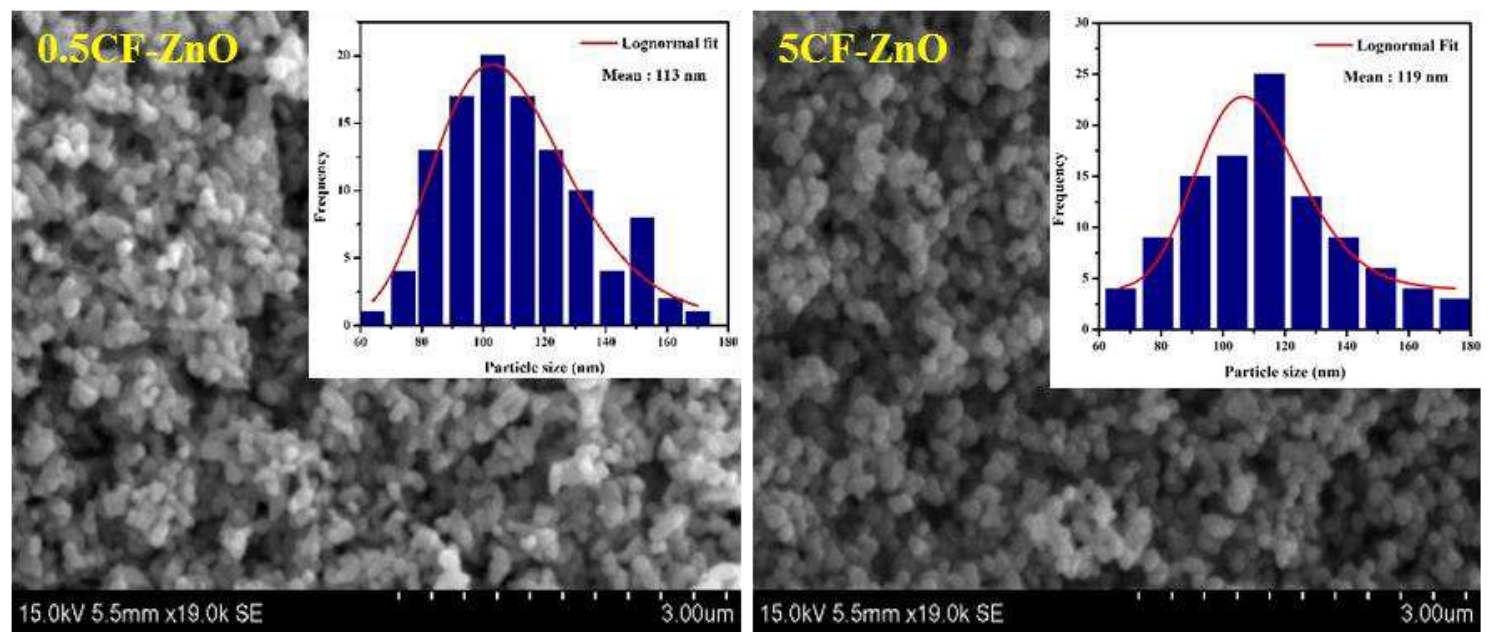

Fig. 3 SEM images of 0.5CF-ZnO and 5CF-ZnO 


\section{Optical analysis}

The optical absorption of the heterostructures was inspected to find the bandgap of the samples. Fig. 4 depicts the absorption spectra of the CF-ZnO system in the UV-Vis region. $\mathrm{ZnO}$ absorbs only in the UV region $(200-400 \mathrm{~nm})$. The band at $354 \mathrm{~nm}$ is attributed to the bandgap excitonic absorption. In CFO, strong absorption in UV region (200-240 nm) was found as well as in the visible region.
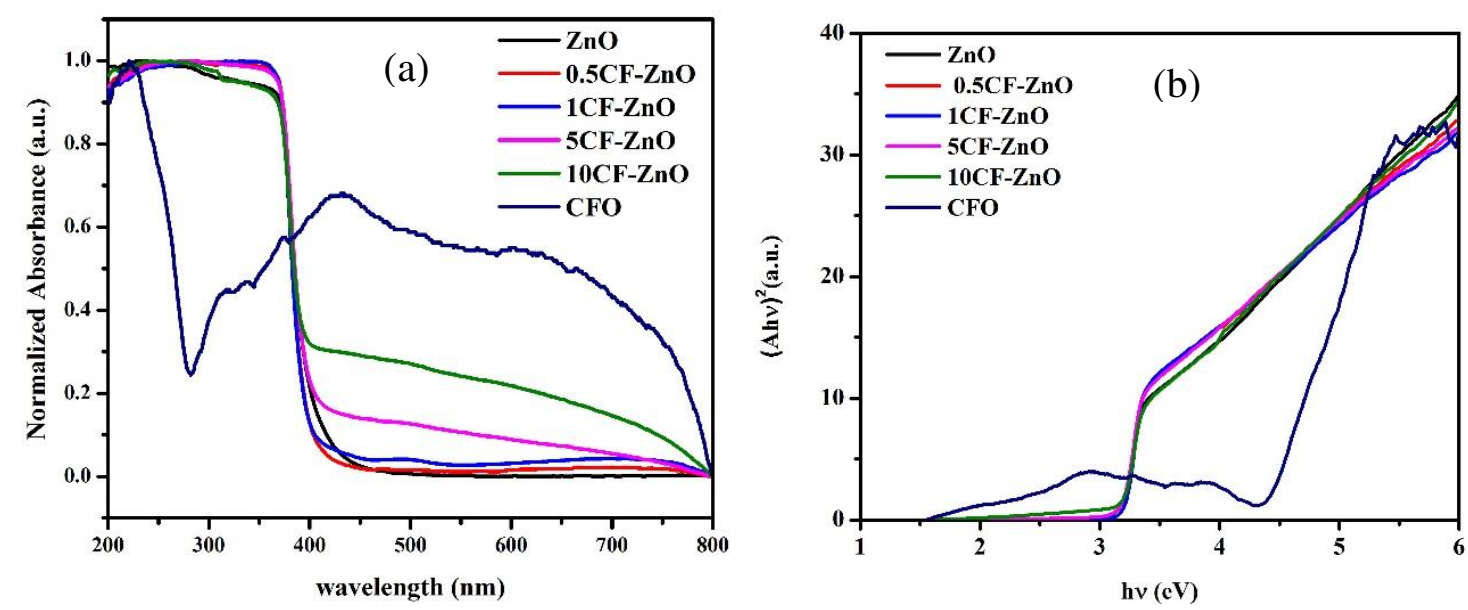

Fig. 4 Absorbance spectra (a) Tau plot (b) of the xCF-ZnO system

The absorption peak between $200-240 \mathrm{~nm}$ in CFO is due to the charge transfer excitation from the valence band to the conduction band [25]. In comparison to $\mathrm{ZnO}$, it can be observed that with an increase in wt $\%$ of $\mathrm{CFO}$ in $\mathrm{ZnO}$, the optical absorption in visible region increases. This indicates the enhanced solar light harvesting property upon forming $\mathrm{ZnO}-\mathrm{CFO}$ heterostructures compared to pure $\mathrm{ZnO}$ which is essential for enhancing the photocatalytic performance. Both $\mathrm{ZnO}$ and $\mathrm{CFO}$ being indirect semiconductors, the bandgap energy was obtained using equation 3

$$
(\alpha h v)^{2}=A\left(h v-E_{g}\right)
$$

where, $\alpha, h, v, A$, and $E_{g}$ are the absorption coefficient, Planck constant, frequency, constant and bandgap, respectively. Extrapolating the plot of $[\alpha \mathrm{h} v]^{2}$ vs. the energy to $\mathrm{x}-\mathrm{axis}$ provides the bandgap. The bandgap values were found to be $3.15,3.19,3.17,3.12,3.11$ and 
$1.5 \mathrm{eV}$ for $\mathrm{ZnO}, 0.5,1,5,10 \mathrm{CF}-\mathrm{ZnO}$ and $\mathrm{CFO}$, respectively. $\mathrm{ZnO}$ with bandgap $3.15 \mathrm{eV}$ absorbs visible light scarcely. But CFO nanoparticles strongly absorb visible light due to their narrow bandgap. Thus combining these two materials would improve the visible light absorption without any change in bandgap.

\section{Photocatalytic activity}

The photocatalytic activity of $\mathrm{xCF}-\mathrm{ZnO}$ heterostructures was evaluated by the photodegradation of methylene blue under sunlight. $20 \mathrm{mg}$ of the $\mathrm{xCF}-\mathrm{ZnO}$ heterostructures was added to $50 \mathrm{ml}$ of methylene blue dye solution with a concentration of $10 \mathrm{mg} / \mathrm{L}$. The combined solution of the respective photocatalyst and dye was stirred in dark for $30 \mathrm{~min}$ to achieve the adsorption-desorption equilibrium. Then, the reactant solution was exposed to sunlight for $60 \mathrm{~min}$. The intensity of the sunlight was noted using a lux meter (85000 lux). The latitude and longitude coordinates were $12^{\circ} 0^{\prime} 56.967^{\prime \prime} \mathrm{N}$ and $79^{\circ} 51^{\prime} 8.978^{\prime \prime} \mathrm{E} .1 \mathrm{ml}$ of the exposed solution was collected at an interval of every $10 \mathrm{~min}$, subsequently centrifuged and was analyzed by UV-Vis spectrophotometer. Fig. 5 shows the UV-Vis absorption spectra for MB degradation by the prepared heterostructures at an interval of $10 \mathrm{~min}$. The degradation efficiency of the respective photocatalysts was evaluated from the UV-Vis spectra using equation 4 ,

$$
\eta(\%)=\frac{C_{0}-C}{C_{0}}
$$

where, $C_{0}$ is the initial concentration at $0 \mathrm{~min}$ and final concentration of the dye at 60 min. Fig. 6a represents the bar diagram of the degradation efficiency of pure $\mathrm{ZnO}, \mathrm{CFO}$ and $\mathrm{CF}-\mathrm{ZnO}$ heterostructures. Pristine $\mathrm{ZnO}$ showed only $38 \%$ degradation of methylene blue at 30 min while $\mathrm{xCF}-\mathrm{ZnO}$ heterostructures showed enhanced degradation efficiency. 5CF-ZnO exhibited $100 \%$ photodegradation in 30 minutes. 

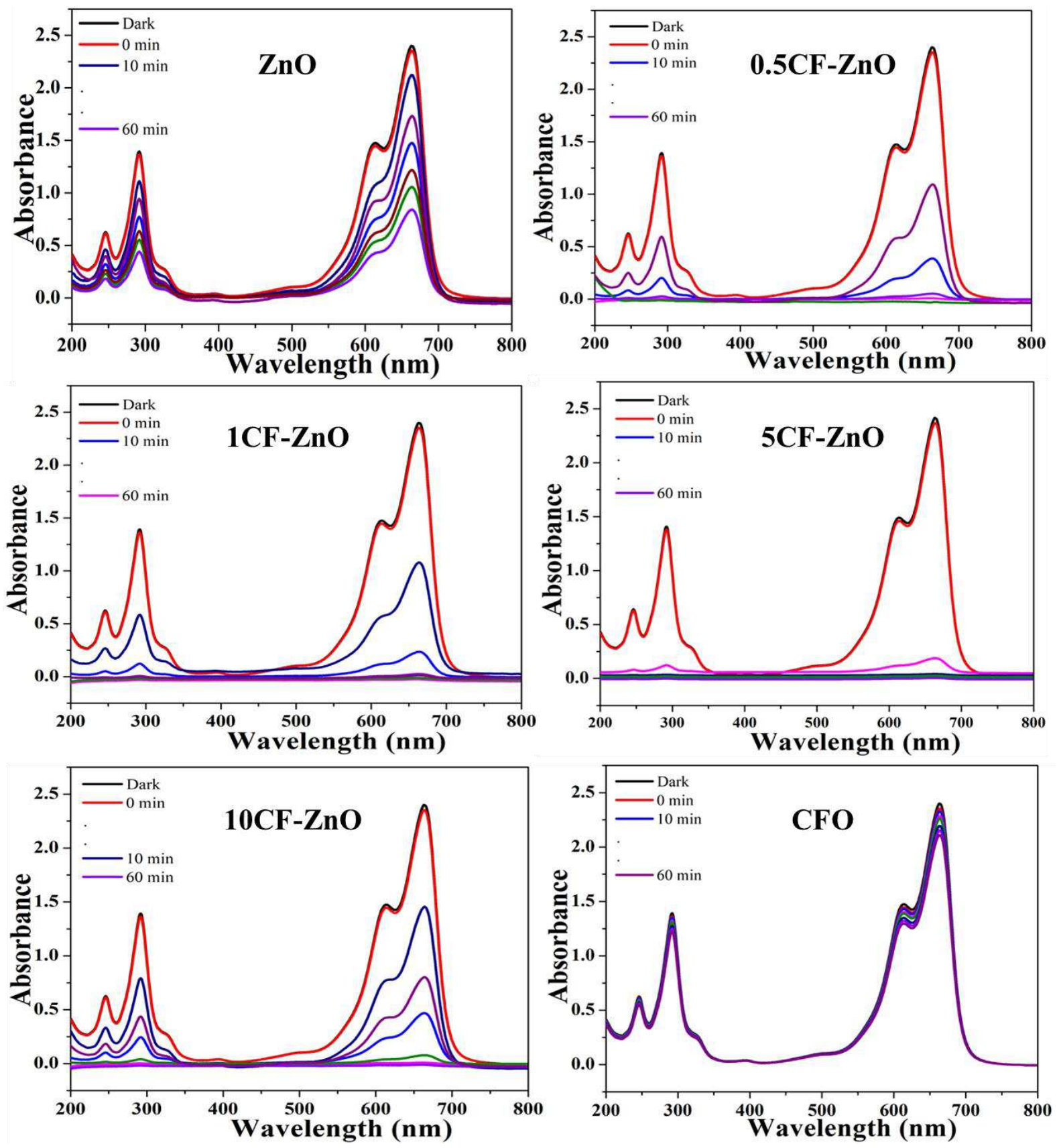

Fig. 5 Absorption spectra for the degradation of methylene blue by sunlight for $\mathrm{ZnO}$ and $\mathrm{xCF}-$ $\mathrm{ZnO}$ system

The increased photocatalytic ability of $\mathrm{xCF}-\mathrm{ZnO}$ can be attributed to the combined effect of $\mathrm{CFO}$ and $\mathrm{ZnO}$. The reaction kinetics for methylene blue degradation was quantified to compare the photocatalytic activity. The reaction exhibited pseudo-first-order kinetics and the rate constant is calculated using equation 4.

$$
C=C_{0} \exp (-\mathrm{kt})
$$


where, $\mathrm{k}$ is the rate constant and $\mathrm{C}$ is the concentration of the dye at different time intervals.

Table 1 displays the rate constant of the prepared catalyst for MB degradation. It is obvious from the table that all $\mathrm{xCF}-\mathrm{ZnO}$ heterostructures showed higher rate constant compared to their pristine counterparts. $5 \mathrm{CF}-\mathrm{ZnO}$ showed the highest rate constant value of $0.272 \mathrm{~min}^{-1}$ among all the samples.
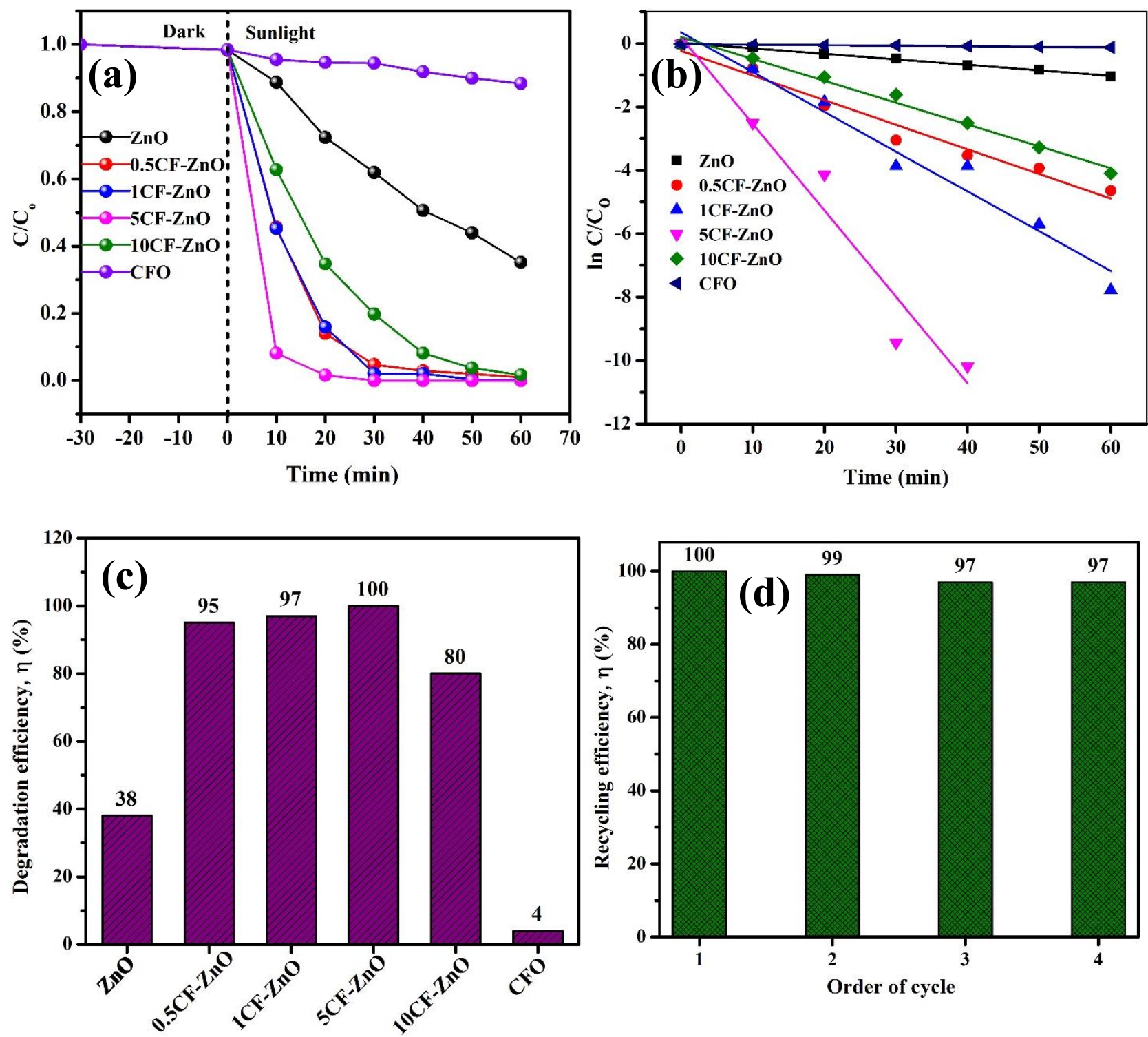

Fig. 6 a) Concentration vs irradiation time profile b) Reaction kinetics c) degradation efficiency at $30 \mathrm{~min}$ of $\mathrm{ZnO}$ and $\mathrm{xCF}-\mathrm{ZnO}$ system for the degradation of methylene blue d) degradation efficiency of $5 \mathrm{CF}-\mathrm{ZnO}$ for consecutive 4 cycles at $30 \mathrm{~min}$ 
Table 1: Rate constant of the samples

\begin{tabular}{|c|c|c|}
\hline S. No. & Sample Code & $\begin{array}{c}\text { Rate Constant } \\
\left(\mathbf{m i n}^{-1}\right)\end{array}$ \\
\hline $\mathbf{1}$ & $\mathrm{ZnO}$ & $0.017 \pm 0.002$ \\
\hline $\mathbf{2}$ & $0.5 \mathrm{CF}-\mathrm{ZnO}$ & $0.077 \pm 0.001$ \\
\hline $\mathbf{3}$ & $1 \mathrm{CF}-\mathrm{ZnO}$ & $0.125 \pm 0.002$ \\
\hline $\mathbf{4}$ & $5 \mathrm{CF}-\mathrm{ZnO}$ & $0.272 \pm 0.002$ \\
\hline $\mathbf{5}$ & $10 \mathrm{CF}-\mathrm{ZnO}$ & $0.068 \pm 0.003$ \\
\hline $\mathbf{6}$ & $\mathrm{CFO}$ & $0.002 \pm 0.001$ \\
\hline
\end{tabular}

The recyclability of the heterostructure was evaluated by sequentially retrieving the sample by centrifuging and drying at $60^{\circ} \mathrm{C}$ for 1 hour after every degradation experiment. $5 \mathrm{CF}-$ $\mathrm{ZnO}$ was tested for recyclability and Fig. S1 shows the UV-Vis absorption spectra for the degradation of methylene blue from $2^{\text {nd }}$ to $4^{\text {th }}$ consecutive cycles. Fig. $6 \mathrm{~d}$ shows the degradation efficiency for 4 consecutive cycles. The degradation reduced only by $3 \%$ which might be due to the weight loss of samples during the recovery process. Thus, the prepared heterostructure showed excellent stable performance. The basis for this enhanced photocatalytic activity by $\mathrm{CF}-\mathrm{ZnO}$ heterostructures is validated by the time resolve photoluminescent study and electrochemical impedance spectroscopic analysis.(Section 3.6)

\section{Photocatalytic Mechanism}

\section{Time-Resolved Photoluminescence Analysis}

To proclaim the constructive effect of heterostructure formation on the photocatalytic performance, the lifetime of the excited charge carriers was measured by TRPL study. The samples were excited at $325 \mathrm{~nm}$ and the photoluminescence decay was monitored at $400 \mathrm{~nm}$.

Fig. 5 depicts the TRPL decay curves for $\mathrm{xCF}-\mathrm{ZnO}$ heterostructures. $\mathrm{ZnO}$ exhibits a 
multiexponential decay process and was fitted using bi-exponential model as represented in equation 4 to obtain two decay times $\tau_{1}$ and $\tau_{2}$.

$$
R(t)=A_{1} e^{\frac{-t}{\tau 1}}+A_{2} e^{\frac{-t}{\tau 2}}
$$

where, $A_{1}$ and $A_{2}$ represent the amplitude. $\tau_{1}$ signifies the time constant for short decay process generated due to quasi-free excitons and $\tau_{2}$ signifies the time for long decay process which is characteristic to localised exciton recombination [26].

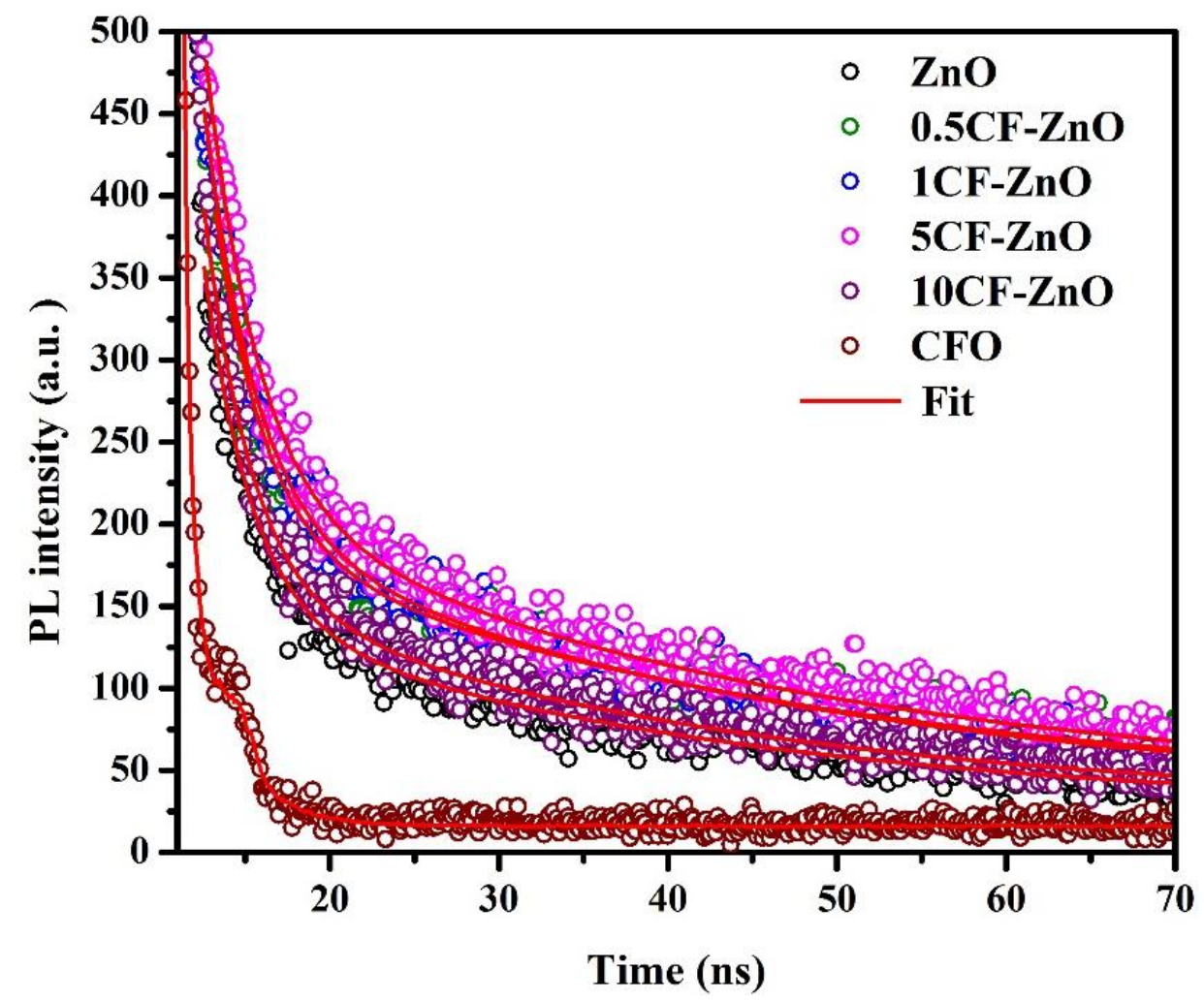

Fig. 5 Time resolved photoluminescent decay of pure $\mathrm{ZnO}, \mathrm{CFO}$ and $\mathrm{xCF}-\mathrm{ZnO}$ heterostructures

The average lifetime ( $\tau_{\text {avg }}$ ) of the charge carriers were calculated from the fitted values using equation 5 and are represented in Table 1.

$$
t_{a v}=\frac{A_{1} * \tau_{1}{ }^{2}+A_{2} * \tau_{2}{ }^{2}}{A_{1} * \tau_{1}+A_{2} * \tau_{2}}
$$


From Table 1, it could be observed that long lifetime increased from $29.6 \mathrm{~ns}$ in $\mathrm{ZnO} 33.4 \mathrm{~ns}$ in 5CF-ZnO. The lifetime increased with increase in weight percentage of $\mathrm{CuFeO}_{2}$ in $\mathrm{ZnO}$ upto $5 \%$ farther on decreased in $10 \mathrm{CF}-\mathrm{ZnO} .5 \mathrm{CF}-\mathrm{ZnO}$ exhibited a pronounced increase in average lifetime of $32.3 \mathrm{~ns}$ while that of $\mathrm{ZnO}$ was only $27.6 \mathrm{~ns}$. This substantiates that the recombination of photogenerated electron -holes is suppressed in $\mathrm{xCF}-\mathrm{ZnO}$ heterostructures leading to enhanced photocatalytic performance.

Table 2: Fitted values of amplitude and time constant obtained from TRPL decay curves and the calculated average life time of charge carriers

\begin{tabular}{|c|c|c|c|c|c|c|}
\hline S.No & Sample & $\boldsymbol{A}_{\mathbf{1}}(\mathbf{\%})$ & $\boldsymbol{A}_{\mathbf{2}}(\mathbf{\%})$ & $\boldsymbol{\tau}_{\mathbf{1}}(\mathbf{n s})$ & $\boldsymbol{\tau}_{\mathbf{2}}(\mathbf{n s})$ & $\boldsymbol{t}_{\boldsymbol{\alpha} \boldsymbol{v}}(\mathbf{n s})$ \\
\hline 1 & $\mathrm{ZnO}$ & 45.5 & 54.5 & 2.78 & 29.6 & 27.6 \\
\hline 2 & $0.5 \mathrm{CF}-\mathrm{ZnO}$ & 29.9 & 70.1 & 3.02 & 31.7 & 22.5 \\
\hline 3 & $1 \mathrm{CF}-\mathrm{ZnO}$ & 30.4 & 69.6 & 3.06 & 32.0 & 23.6 \\
\hline 4 & $5 \mathrm{CF}-\mathrm{ZnO}$ & 30.1 & 69.9 & 2.93 & 33.4 & 32.3 \\
\hline 5 & $10 \mathrm{CF}-\mathrm{ZnO}$ & 42.8 & 60.2 & 2.81 & 30.6 & 28.9 \\
\hline 6 & $\mathrm{CFO}$ & 27.9 & 97.21 & 0.2 & 2.69 & 0.85 \\
\hline
\end{tabular}

\section{Electrochemical Impedance spectroscopy}

To explore the charge transfer dynamics of the heterostructures for the enhanced photocatalytic activity, the electrochemical analysis was done. Fig. 6 shows the Nyquist plot of $\mathrm{xCF}-\mathrm{ZnO}$ the samples. The charge transfer resistance is calculated by fitting the Nyquist plot using an equivalent circuit consisting of resistor $R_{1}$ in series with $R_{C T} \| C P E$, where $R_{1}$ is the solution resistance and $\mathrm{R}_{\mathrm{CT}}$ is the charge transfer resistance and CFE denotes the constant phase element. The calculated $\mathrm{R}_{\mathrm{CT}}$ values for $\mathrm{ZnO}, 0.5 \mathrm{CF}-\mathrm{ZnO}, 1 \mathrm{CF}-\mathrm{ZnO}, 5 \mathrm{CF}-\mathrm{ZnO}, 10 \mathrm{CF}-\mathrm{ZnO}$ and CFO are 70, 33, 29, 19, 42 and $180 \mathrm{k} \Omega$, respectively. This clearly depicts that the formation of 
$\mathrm{CF}-\mathrm{ZnO}$ heterostructure mitigated the charge transfer resistance which implies faster transfer of photogenerated charge carriers between n-type $\mathrm{ZnO}$ and p-type $\mathrm{CFO}$.

Mott-Schottky analysis was done to probe the alignment of band structure in CFO and $\mathrm{ZnO}$. The relative position of the valence band and the conduction band of $\mathrm{ZnO}, \mathrm{CuFeO}_{2}$ were evaluated from the flat band potential $\left(\mathrm{V}_{\mathrm{fb}}\right)$ and the bandgap values. Fig. 7 depicts the MottSchottky (M-S) curves of $\mathrm{CFO}$ and $\mathrm{ZnO}$. A positive/negative slope indicates that the $\mathrm{CFO} / \mathrm{ZnO}$ is an n-type/p-type and affirms that electrons/holes are the majority of the charge carriers. $\mathrm{V}_{\mathrm{fb}}$ was obtained by extrapolating the plot of $1 / C^{2}$ vs potential to $\mathrm{X}$-axis. The flat band potential of

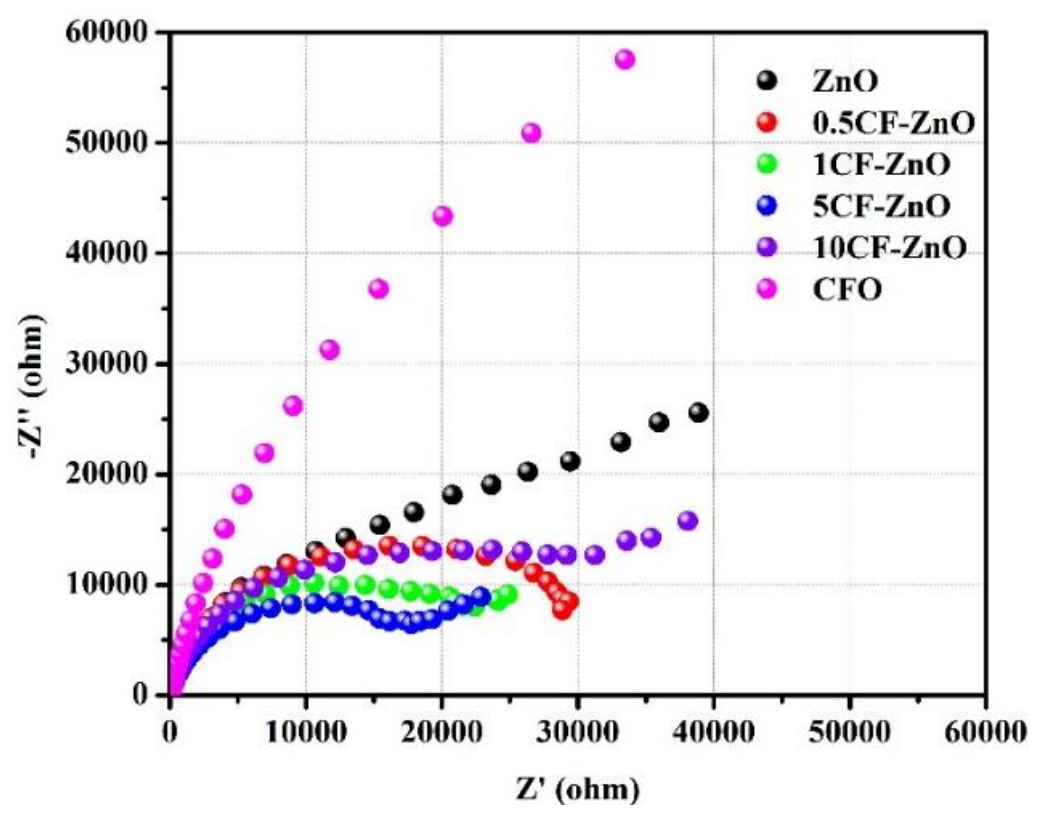

Fig. 6 Nyquist plot and Mott Schottky plot of xCF-ZnO system

$\mathrm{ZnO}$ and $\mathrm{CuFeO}_{2}$ was calculated to be -0.82 and $1.17 \mathrm{eV}$ vs $\mathrm{Ag} / \mathrm{AgCl}$, respectively. It is well known from literature, that the difference between the flat-band potential and the bottom/top edge of the conduction/valence band is negligible for an-type/p-type material [27]. Hence, we assume the value of flat band potential as the conduction/ valence band edge for $n$ and $p$-type semiconductor, respectively. The band structure alignment between $\mathrm{ZnO}$ and $\mathrm{CFO}$ identified using flat-band potentials and bandgap energy using equation 6.

$$
E_{C B}=E_{V B}-E_{g}
$$



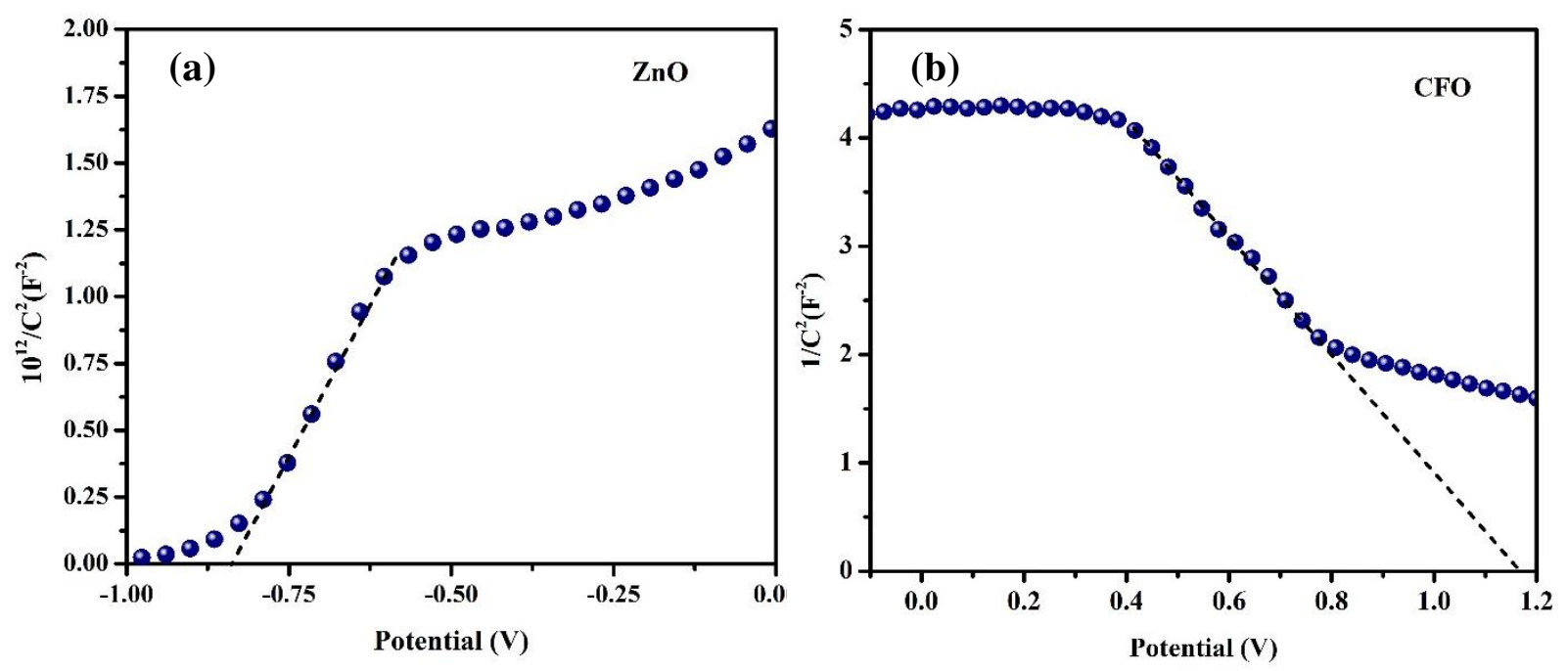

Fig. 7 Mott-Schottky plots of (a) $\mathrm{ZnO}$ and (b) $\mathrm{CuFeO}_{2}$.

According to the calculated values of energy bands, the photocatalytic degradation mechanism of CF-ZnO heterostructures was proposed as shown in Fig. 8. The energy levels of CFO lies within the energy levels of $\mathrm{ZnO}$ forming a Type 1 Straddling type $\mathrm{p}-\mathrm{n}$ heterostructure. After the contact formation, the energy levels of $\mathrm{CuFeO}_{2}$ shifts upwards while the energy levels of $\mathrm{ZnO}$ are shifted downwards until the Fermi levels of $\mathrm{CFO}$ and $\mathrm{ZnO}$ forms an equilibrium. This results in the conduction band edge of CFO higher than $\mathrm{ZnO}$. In consequence, an inner electric field is formed between the $\mathrm{p}-\mathrm{CFO}$ and $\mathrm{n}-\mathrm{ZnO}$ with minority charge carriers. When exposed to sunlight, $\mathrm{CFO}$ and $\mathrm{ZnO}$ absorbs photons and generate electron-hole pairs. The excited electrons migrate from the conduction band of $\mathrm{CFO}$ to the surface of $\mathrm{ZnO}$ across the interface. Simultaneously, the holes are transferred from the valence band of $\mathrm{ZnO}$ to CFO due to the more negative VB potential of CFO than that of the $\mathrm{ZnO}$. This transfer of $\mathrm{h}^{+}$and $\mathrm{e}^{-}$ in the opposite direction increases the lifetime of photo-generated charge carriers in the heterostructures. The oxygen dissolved in the aqueous solution adsorb on the surface of the photocatalyst and react with these excited electrons and generate active free radical ${ }^{\circ} \mathrm{O}_{2}$. Simultaneously, the holes react with $\mathrm{H}_{2} \mathrm{O}$ to produce ${ }^{\circ} \mathrm{OH}$ free radicals. This effectuates the degradation of methylene blue which are adsorbed on the surface of the photocatalyst by the 
free radicals. Thus the formation of $\mathrm{CF}-\mathrm{ZnO}$ heterostructure promoted faster transfer of electrons and holes between $\mathrm{ZnO}$ and $\mathrm{CFO}$ and subsequently hindered the recombination of photon generated electrons and holes, thereby enhancing the photocatalytic degradation.

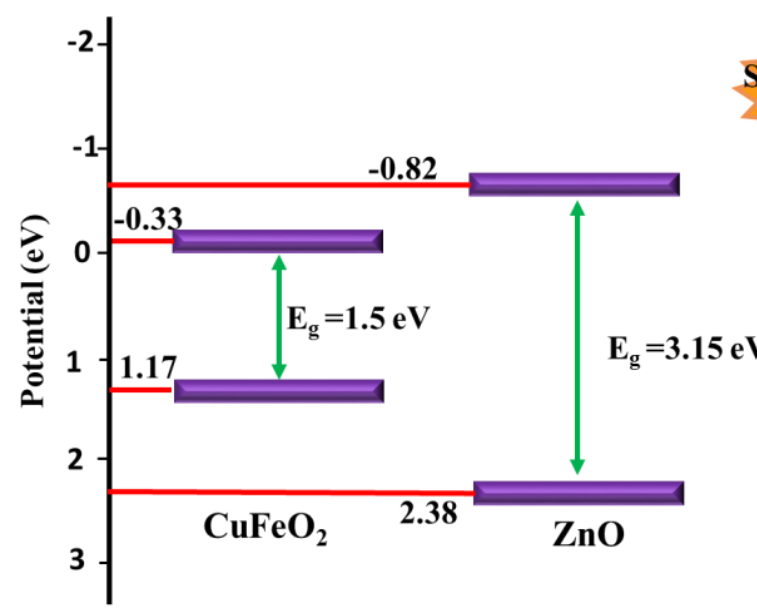

a) Before contact

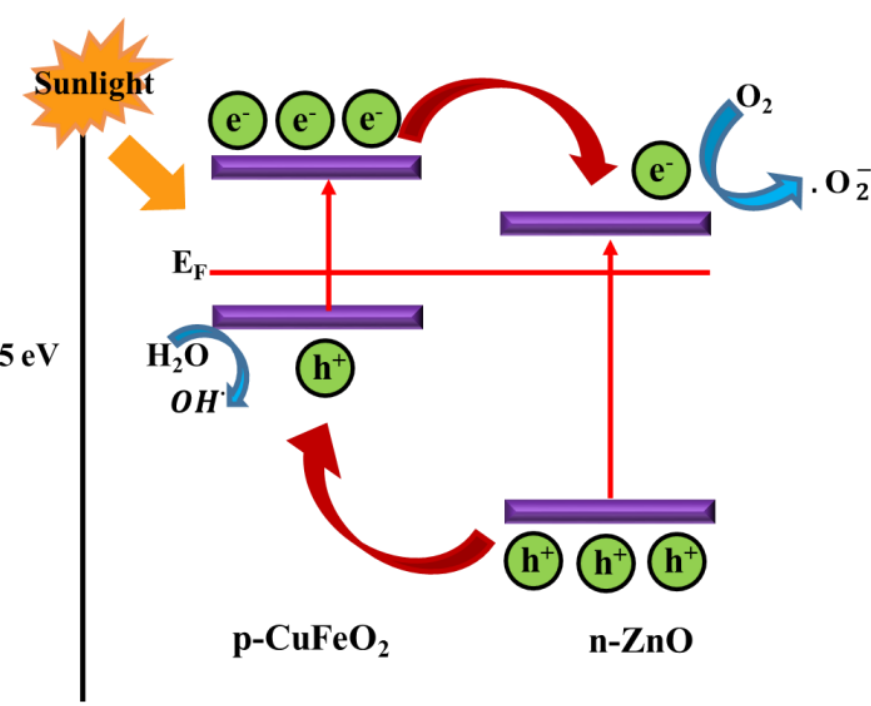

b)After contact

Fig. 8 Schematic diagram for the photocatalytic mechanism of CF-ZnO heterostructures

\section{Conclusion}

The present study focuses on developing novel p-n $\mathrm{CuFeO}_{2}-\mathrm{ZnO}$ heterostructure by two- step precipitation - hydrothermal method. The weight ratios of $\mathrm{p}-\mathrm{CuFeO}_{2}$ and $\mathrm{n}-\mathrm{ZnO}$ has a crucial role to control the photocatalytic property. A 16 fold increase in rate constant was observed for $5 \mathrm{CF}-\mathrm{ZnO}$ compared to $\mathrm{ZnO}$ for the photodegradation of methylene blue. TRPL study identified the increase in lifetime of charge carriers in the heterostructure. Flat band potential identification by Mott-Schottky analysis revealed the formation of Type 1 p-n heterostructure. Further electrochemical analysis validates faster charge transfer occurred in 5 wt $\% \mathrm{CuFeO}_{2}-\mathrm{ZnO}$ with lower charge transfer resistance. It could be identified from the results that the proposed $\mathrm{p}-\mathrm{n}$ junction engineering of $\mathrm{CuFeO}_{2}-\mathrm{ZnO}$ enhanced the photodegradation of methylene blue by enhanced visible light absorption, lowered charge transfer resistance and 
charge carrier recombination. Overall, this strategy of creating p-n heterostructure would pave the way for developing other efficient solar harvesting devices.

\section{Declarations}

Funding: The authors acknowledge the funding from DST-SERB (EMR/2016/007577). Two of the authors, Dr.S.Preethi and Dr.S.Vivek thank the CSIR for Research Associateship and Senior Research Fellowship, respectively.

Conflicts of interest: The authors declare no conflict of interest.

\section{References:}

[1] K. Nakata, A. Fujishima, J.Photochem. Photobio.C: Photochem.Rev. 13, 169-189 (2012).

[2] S. Bhatia, N.Verma, Mater.Res.Bull. 95, 468-476 (2017).

[3] M. Hojamberdiev, B.Czech, A. C.Göktaş, K.Yubuta, Z.C.Kadirova, J. Alloys Compd. 827, 154339 (2020).

[4] L. Cheng, Q,Xiang, Y, Liao, H. Zhang, Energy Environ. Sci. 11, 1362-1391 (2018).

[5] S. K. Jayaraj, P. Thangadurai, J. Mol. Liq. 319, 114368 (2020).

[6] X. Liu, H. Zhai, P. Wang, Q.Zhang, Z. Wang, Y. Liu, Y. Dai, B. Huang, X. Qin and X.Zhang, Catal. Sci. Technol. 9, 652-658 (2019)

[7] C.N.C. Hitam, A.A.Jalil, J. Environ. Manage. 258, 110050 (2020).

[8] C.B. Ong, L. Y. Ng, A.W. Mohammad, Renewable Sustainable Energy Rev. 81, 536-551. (2019)

[9] D.M. Song, J.C. Li, Comput. Mater. Sci. 65,175-81 (2012).

[10] M. Ahmad, E. Ahmed, Y. Zhang, N.R. Khalid, J. Xu, M. Ullah, Curr. Appl.Phys. 103, 13, 697-704 (2013).

[11] S.M. Ng, D.S.N. Wong, J.H.C. Phung, H.S. Chua. Talanta 116, 514-519 (2013).

[12] L. Qi, H. Li, L. Dong, Mater. Lett. 107, 354-356 (2013).

[13] A.Meng, S. Wu, B. Cheng, J. Yu , J.Xu, J. Mater. Chem. A 6, 4729-4736 (2018).

[14] S. K.Lakhera, R.Venkataramana, G. Mathew, H.Y.Hafeez, B. Neppolian, Mater. Sci. Semicond. Process. 106, 104756 (2020).

[15] Y. Jiang, Y.Sun, H. Liu, F. Zhu, H. Yin, Dyes Pigm. 78, 77-83 (2008).

[16] Md. T. Uddin, Y. Nicolas,C. Olivier,T. Toupance, L. Servant,M. M. Müller, H.-J. Kleebe, J.Ziegler, W. Jaegermann, Inorg. Chem. 51, 7764-7773(2012). 
[17] M. Mansournia, L. Ghaderi, J. Alloys Compds. 691,171-177 (2017).

[18] S. Mridha, D. Basak, Semicond. Sci. Technol. 21, 928-9320 (2006).

[19] P. Sathishkumar, R. Sweena, J. J. Wu. S. Anandan, Chem.Eng. J. 171, 136-140 (2011).

[20] A.R. M. Shaheer, V.Vinesh, S. K.Lakher, B. Neppolian, Sol.Energy 213, 260-270 (2021).

[21] J.T. Adeleke, T. Theivasanthi, M. Thiruppathi, M. Swaminathan, T. Akomolafe, A.B. Alab, Appl. Surf. Sci. 455, 195-200 (2018).

[22] C.G. Read, Y. Park, K.S. Choi, J. Phys. Chem. Lett. 14, 1872-1876 (2012).

[23] M. S. Prévot, N. Guijarro, K. Sivula, Chem. Sus. Chem. 8, 1359-1367 (2015).

[24] R. Zhang, P.-G. Yin, N. Wang, L.Guo, Solid State Sci. 11,865-869 (2009).

[25] L. Naka-in, T. Kamwanna, P. Srepusharawoot, S. Pinitsoontorn, V.Amornkitbamrung, Jpn J. Appl. Phys. 54, 04DH10n(2015).

[26] B. Tian, B.J. Yang, J. Li, Z. Li, W.L. Zhen, Y.Q. Wu, G.X. Lu, J. Catal. 350, 189- 196 (2017).

[27] T. Jiang, Y. Zhao, H. Xue, J. Mater. Sci. 54, 11951-11958 (2019). 


\section{Supplementary Information}

Enhanced photocatalytic performance of $\mathrm{CuFeO}_{2}-\mathrm{ZnO}$ heterostructures for methylene blue degradation under sunlight

S. Preethi ${ }^{\text {a }}$, S.Vivek ${ }^{\text {a }}$, R.Priya ${ }^{\mathrm{b}}$, S. Balakumar ${ }^{\mathrm{b}}$, K. Suresh Babu ${ }^{\mathrm{a}, *}$

${ }^{a}$ Centre for Nanoscience and Technology, Madanjeet School of Green Energy Technologies, Pondicherry University (A Central University), Puducherry, 605014, India

${ }^{\mathrm{b}}$ National Centre for Nanoscience and Nanotechnology, University of Madras, Tamilnadu, India.

* Corresponding Author

E mail: sureshbabu.nst@pondiuni.edu.in

Phone: +91-413-2654976
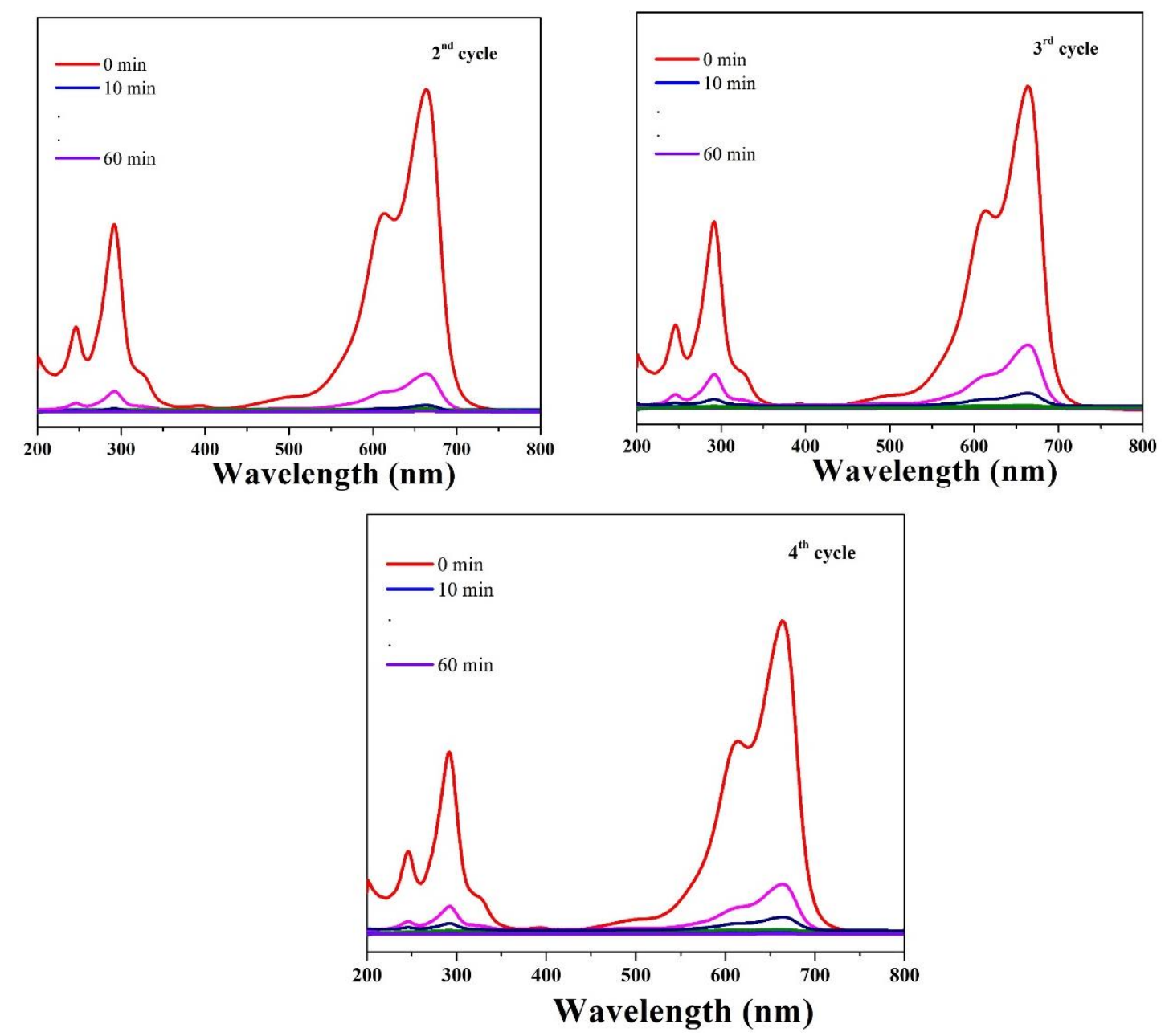

Figure S1. UV-Vis absorption spectra showing photodegradation of MB under sunlight irradiation for 4 cycles ( $1^{\text {st }}$ cycle in the manuscript). 
Figures

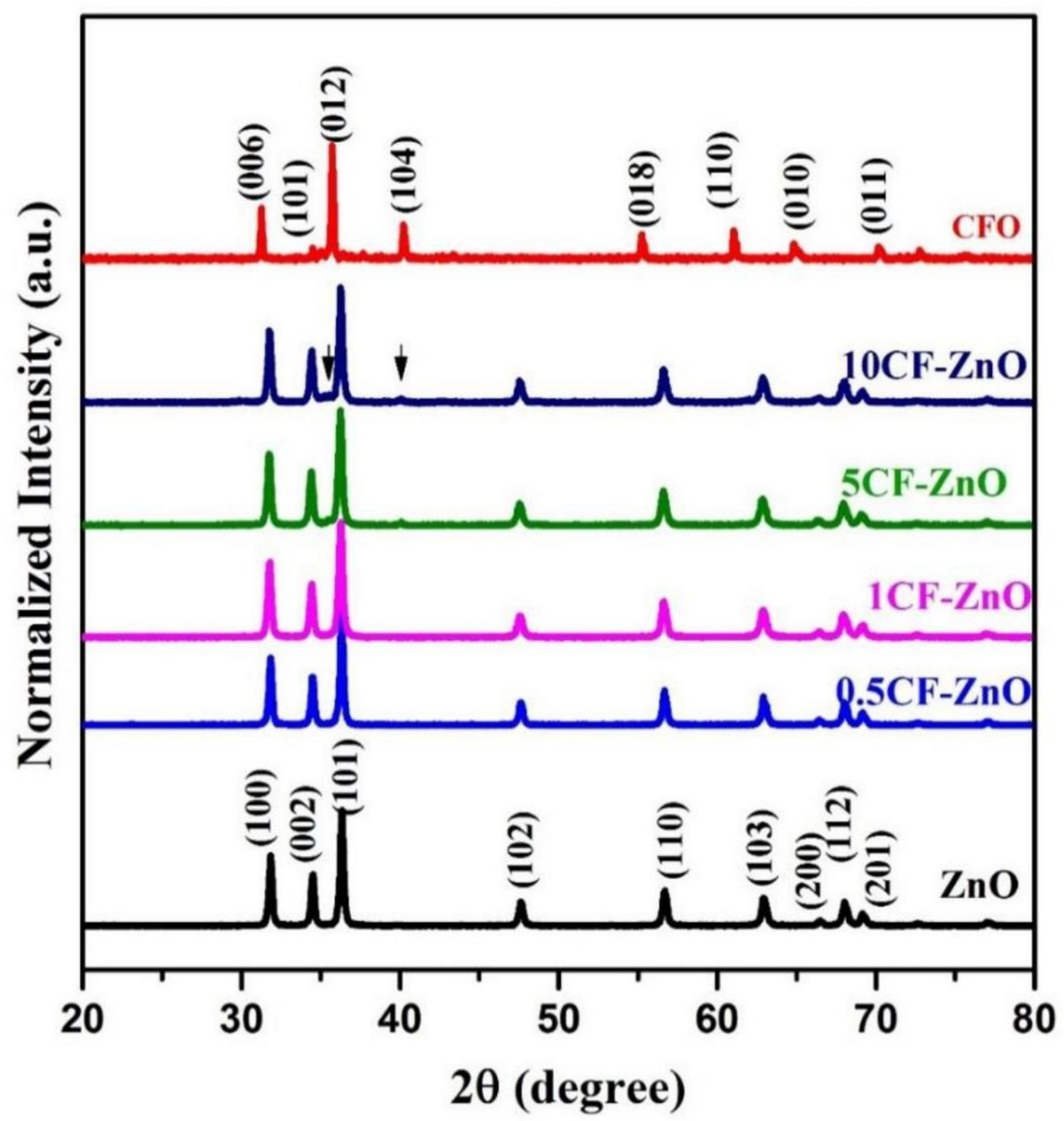

Figure 1

$\mathrm{XRD}$ pattern of pure $\mathrm{ZnO}, \mathrm{xCF}-\mathrm{ZnO}(\mathrm{x}=0.5,1,5,10)$ and pure $\mathrm{CFO}$. The peaks marked with arrow corresponds to $\mathrm{CuFeO} 2$ 


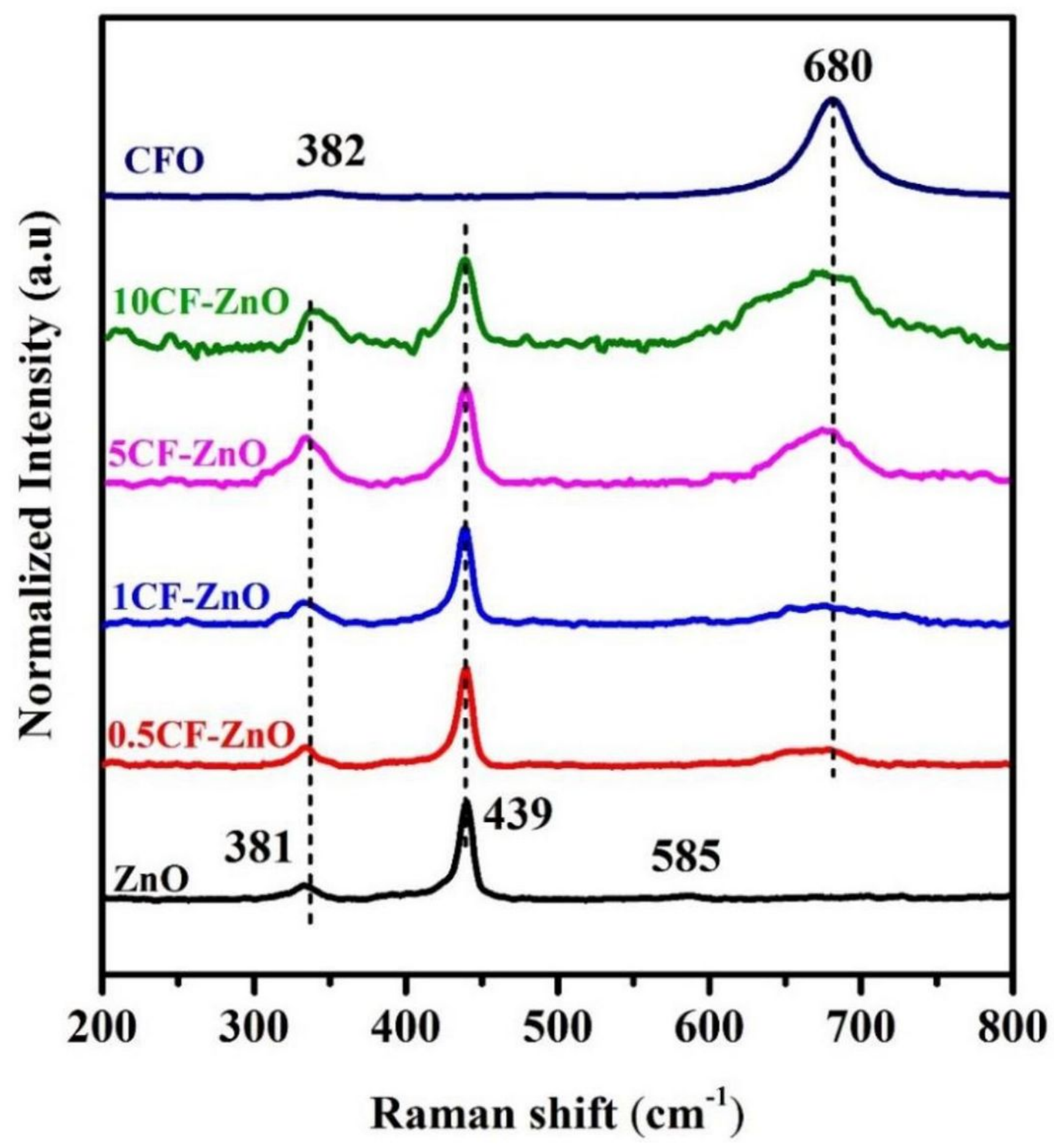

Figure 2

Raman spectra of ZnO, CFO and xCF-ZnO system 

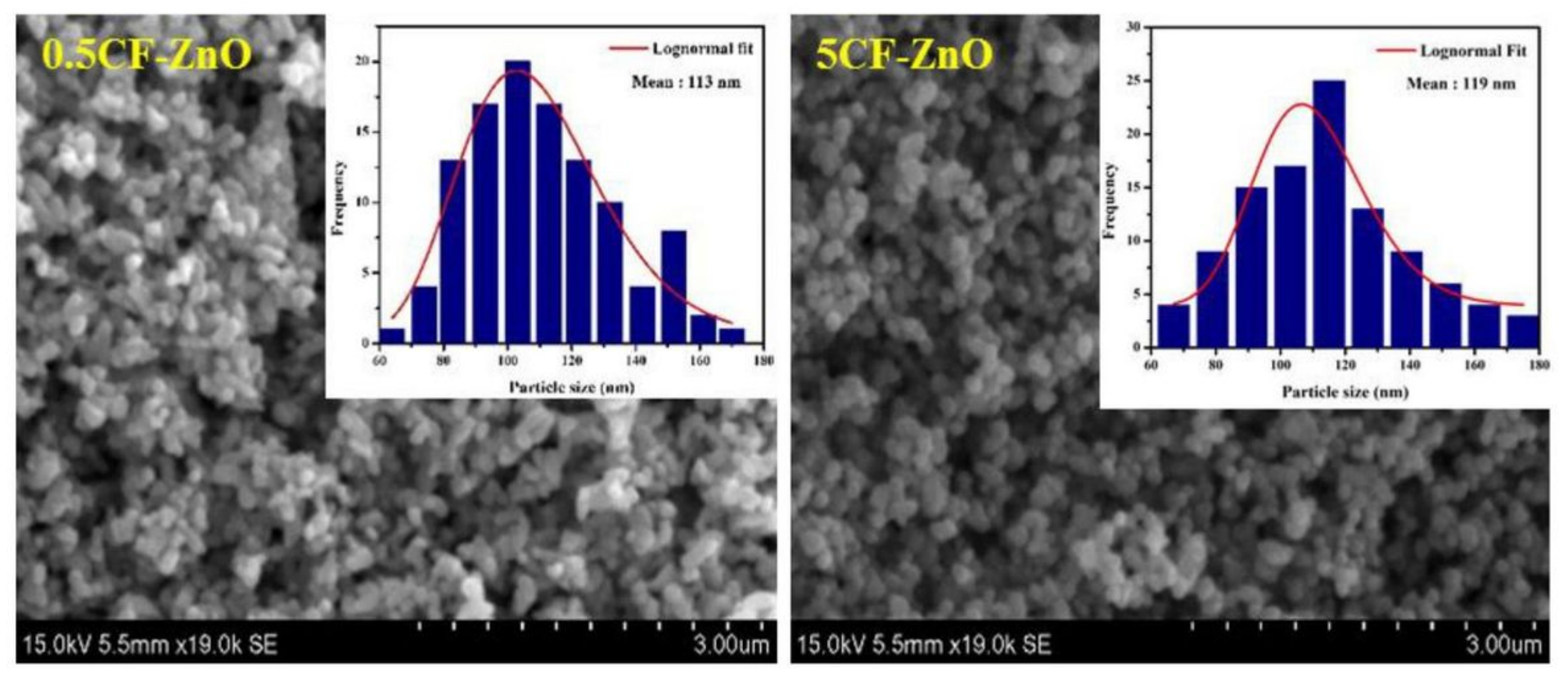

Figure 3

SEM images of 0.5CF-ZnO and 5CF-ZnO
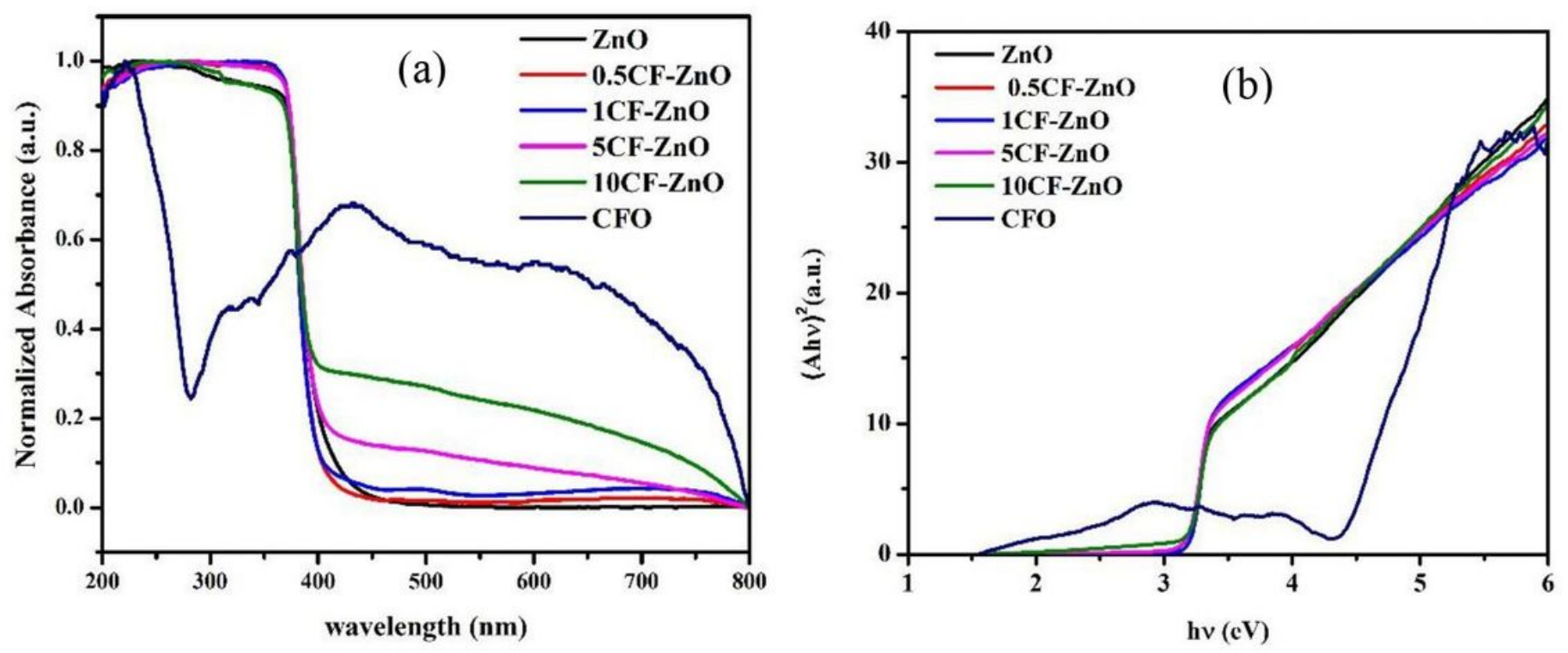

Figure 4

Absorbance spectra (a) Tau plot (b) of the XCF-ZnO system 

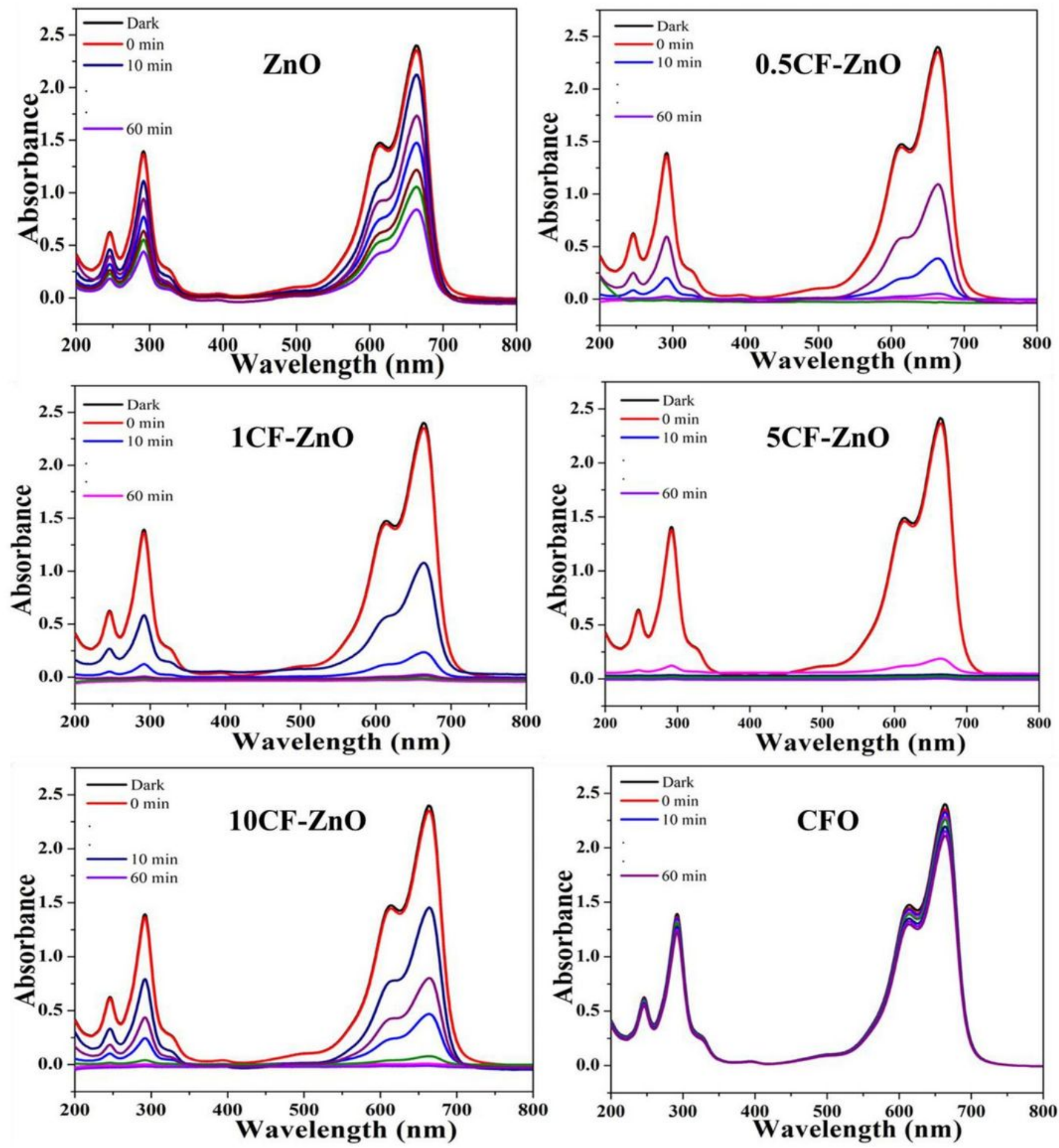

Figure 5

Absorption spectra for the degradation of methylene blue by sunlight for $\mathrm{ZnO}$ and $\mathrm{xCFZnO}$ system 

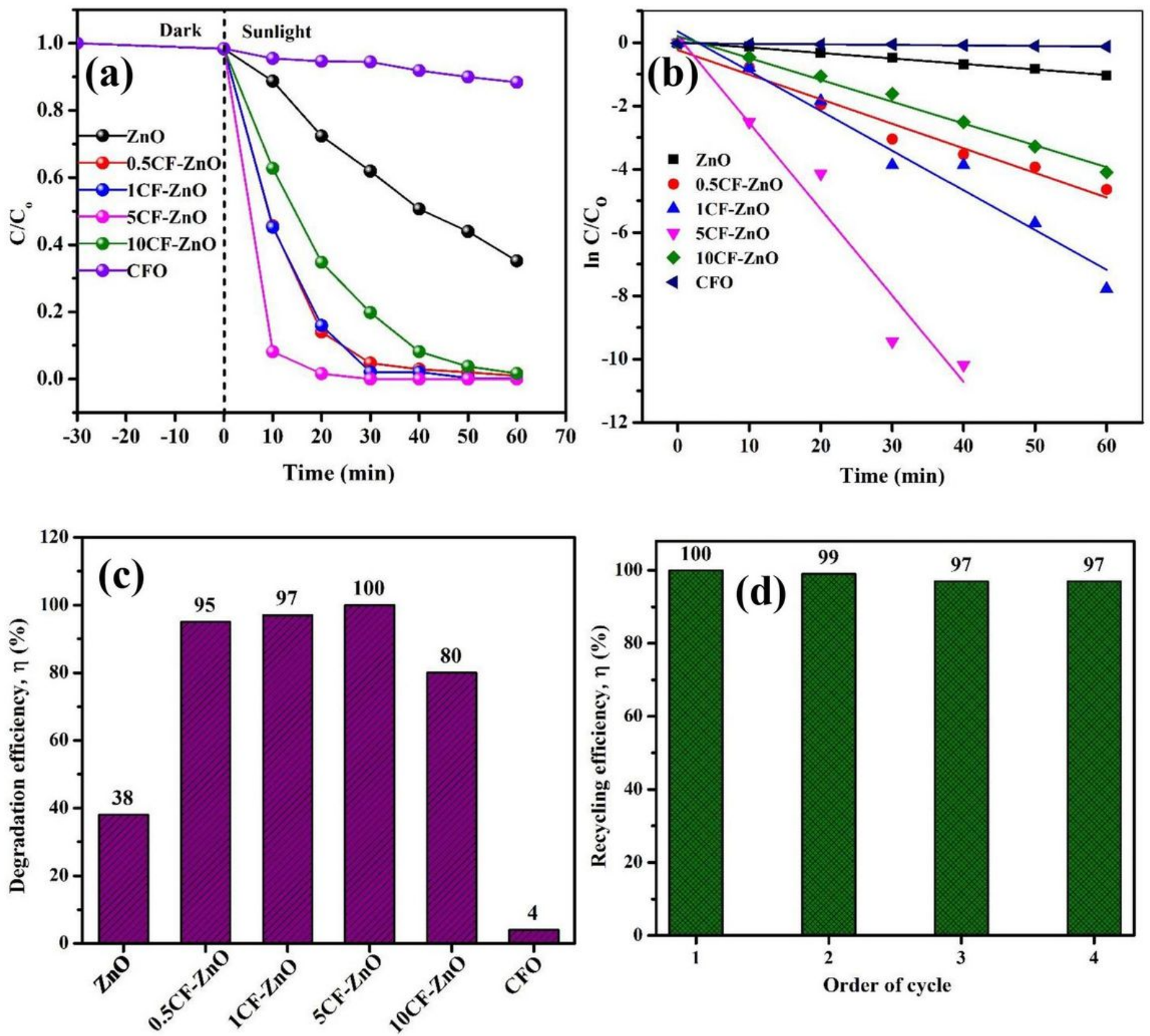

Figure 6

a) Concentration vs irradiation time profile b) Reaction kinetics c) degradation efficiency at 30 min of $\mathrm{ZnO}$ and XCF-ZnO system for the degradation of methylene blue d) degradation efficiency of 5CF-ZnO for consecutive 4 cycles at 30 min 


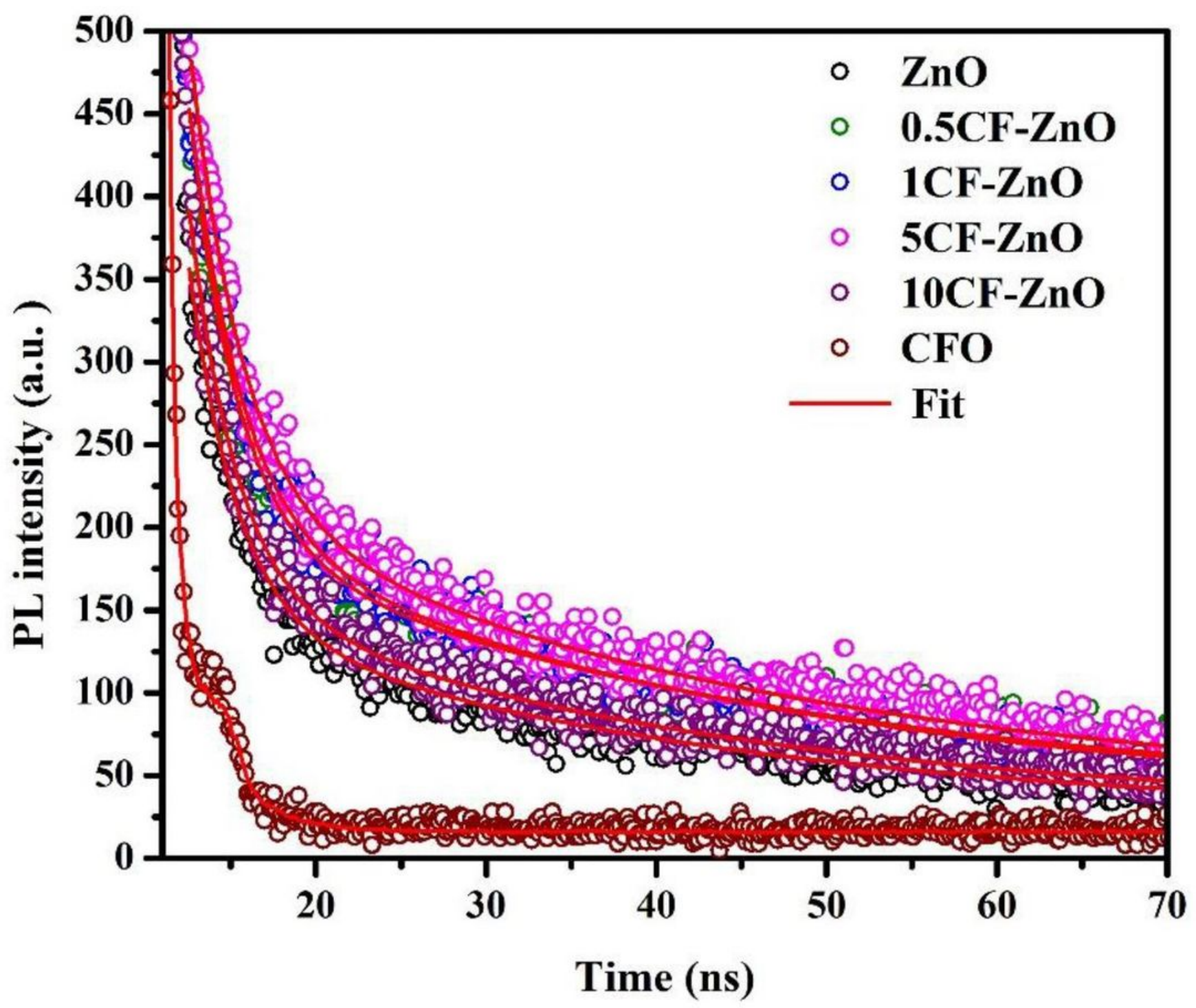

Figure 7

Time resolved photoluminescent decay of pure $\mathrm{ZnO}, \mathrm{CFO}$ and $\mathrm{xCF}-\mathrm{ZnO}$ heterostructures 


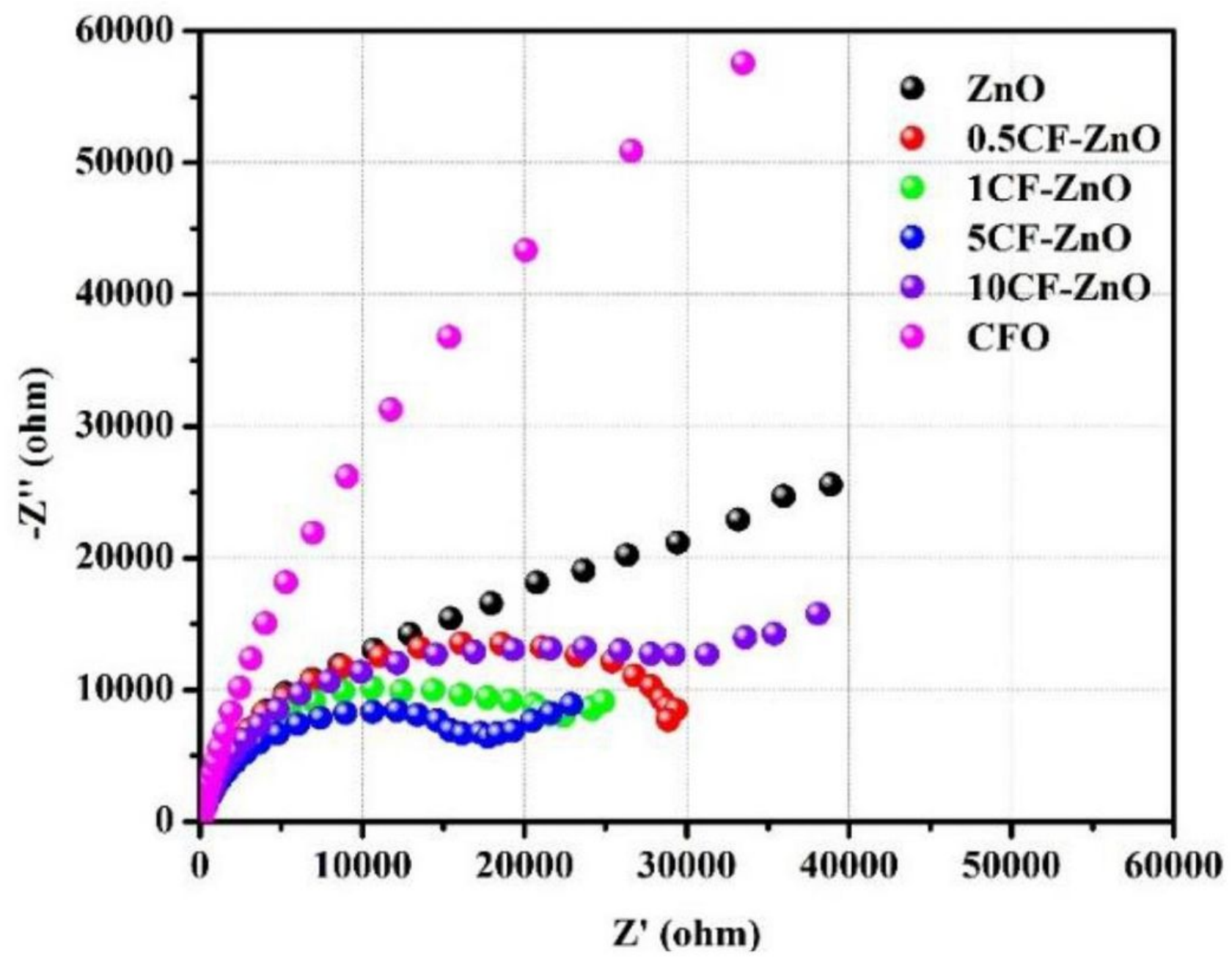

Figure 8

Nyquist plot and Mott Schottky plot of xCF-ZnO system
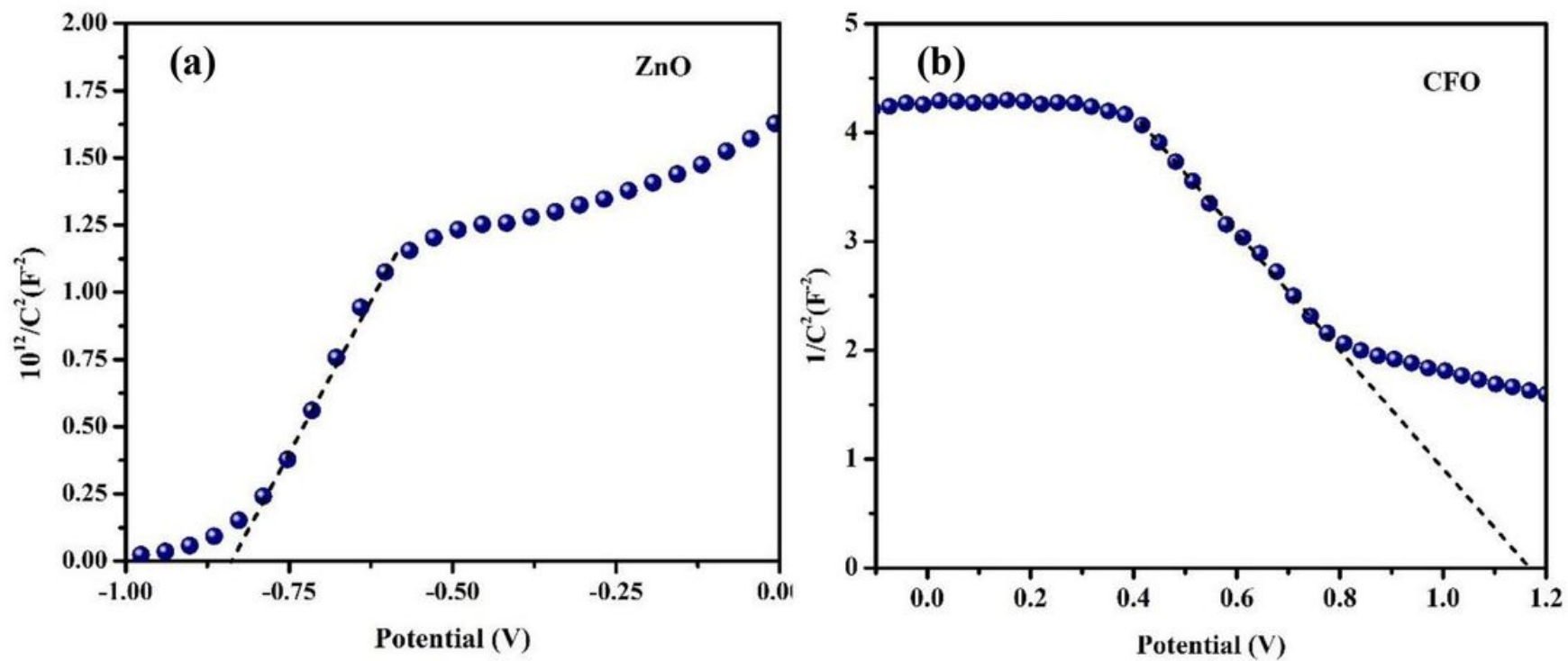

Figure 9 
Mott-Schottky plots of (a) ZnO and (b) CuFeO2.

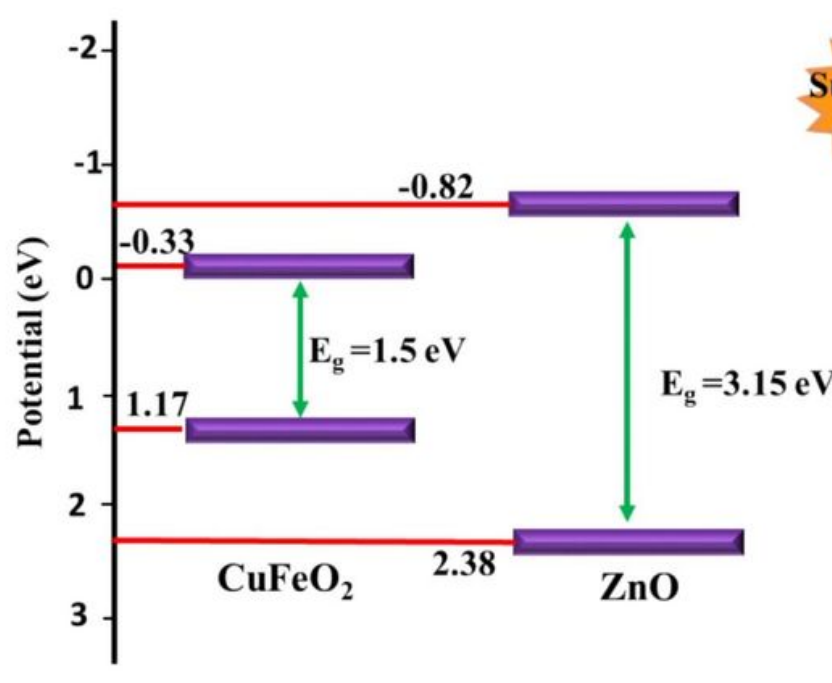

a) Before contact

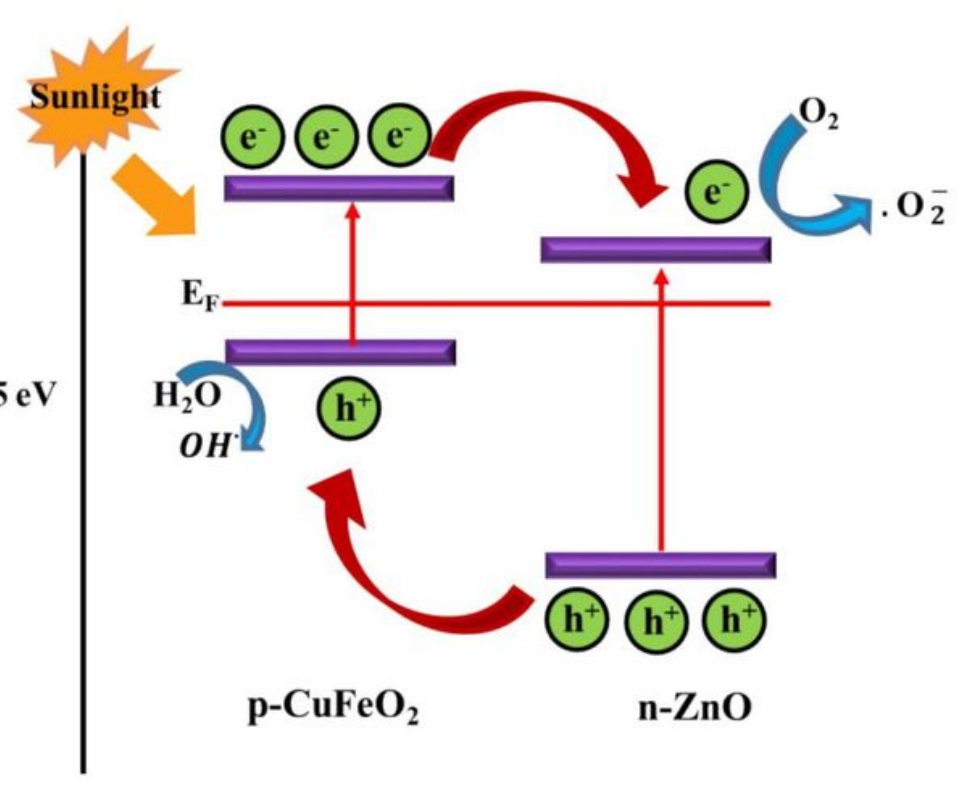

b)After contact

Figure 10

Schematic diagram for the photocatalytic mechanism of CF-ZnO heterostructures 